ARTICLE

\title{
Synergistic ultraviolet and visible light photo- activation enables intensified low-temperature methanol synthesis over copper/zinc oxide/alumina
}

\author{
Bingqiao Xie (10 1,7, Roong Jien Wong (10) 2,3,7, Tze Hao Tan', Michael Higham (10) 3,4, Emma K. Gibson (1) 3,5, \\ Donato Decarolis ${ }^{3,4}$, June Callison (10 3,4, Kondo-Francois Aguey-Zinsou', Michael Bowker ${ }^{3,4}$, \\ C. Richard A. Catlow ${ }^{3,4,6}$, Jason Scott ${ }^{1 凶} \&$ Rose Amal ${ }^{1 凶}$
}

Although photoexcitation has been employed to unlock the low-temperature equilibrium regimes of thermal catalysis, mechanism underlining potential interplay between electron excitations and surface chemical processes remains elusive. Here, we report an associative zinc oxide band-gap excitation and copper plasmonic excitation that can cooperatively promote methanol-production at the copper-zinc oxide interfacial perimeter of copper/zinc oxide/alumina (CZA) catalyst. Conversely, selective excitation of individual components only leads to the promotion of carbon monoxide production. Accompanied by the variation in surface copper oxidation state and local electronic structure of zinc, electrons originating from the zinc oxide excitation and copper plasmonic excitation serve to activate surface adsorbates, catalysing key elementary processes (namely formate conversion and hydrogen molecule activation), thus providing one explanation for the observed photothermal activity. These observations give valuable insights into the key elementary processes occurring on the surface of the CZA catalyst under light-heat dual activation.

\footnotetext{
${ }^{1}$ School of Chemical Engineering, UNSW Australia, Sydney, NSW 2052, Australia. ${ }^{2}$ Applied Chemistry and Environmental Science, School of Science, RMIT University, Melbourne, VIC 3000, Australia. ${ }^{3}$ UK Catalysis Hub, Research Complex at Harwell, Rutherford Appleton Laboratory, Harwell, Oxon OX11 OFA, UK. ${ }^{4}$ School of Chemistry, Cardiff University, Park Place, Cardiff CF10 1AT, UK. ${ }^{5}$ School of Chemistry, Joseph Black Building, University of Glasgow, Glasgow G12 8QQ, UK. ${ }^{6}$ Department of Chemistry, University College London, 20 Gordon St, London WC1 HOAJ, UK. ${ }^{7}$ These authors contributed equally: Bingqiao Xie,

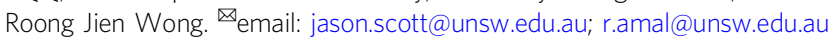


$\mathrm{R}$ eferred to as a "methanol economy", methanol (MeOH) synthesis from the chemical recycling of $\mathrm{CO}_{2}$ is considered a promising approach to reduce atmospheric $\mathrm{CO}_{2}$ levels and the dependence on fossil fuels since $\mathrm{MeOH}$ can be readily utilised as a liquid fuel and is well-established as a carbon feedstock material. Despite its potential, the $\mathrm{CO}_{2}$-to- $\mathrm{MeOH}$ reaction is inherently restricted by thermodynamic limitations and energyintensive operational conditions $s^{2,3}$. While elevated temperatures $\left(>240{ }^{\circ} \mathrm{C}\right)$ favour $\mathrm{CO}_{2}$ activation, they are detrimental towards $\mathrm{MeOH}$ production due to the exothermic nature of the reaction and the presence of the competitive reverse water gas shift (RWGS) reaction at higher temperatures ${ }^{4,5}$.

Despite the emergence of new catalysts for the $\mathrm{CO}_{2}$-to- $\mathrm{MeOH}$ reaction $^{6,7}$, the industrially relevant and well-established $\mathrm{Cu} /$ $\mathrm{ZnO} / \mathrm{Al}_{2} \mathrm{O}_{3}(\mathrm{CZA})$ catalyst $(\mathrm{Cu}$ loading of $30-70$ at.\%) remains one of the most active $\mathrm{MeOH}$-production catalysts in terms of both turn-over frequency (TOF, based on $\mathrm{Cu}$ active sites) and $\mathrm{MeOH}$ yield. The advantages of the CZA originate from the distinctive $\mathrm{ZnO}$ promotion in the stabilisation of intermediates involved in $\mathrm{CO}_{2}$ hydrogenation over the $\mathrm{Cu}-\mathrm{ZnO}$ system ${ }^{8}$. Recent studies on $\mathrm{Cu}-\mathrm{ZnO}$ catalyst suggested that the $\mathrm{Cu}-\mathrm{ZnO}$ interface may provide active sites for multiple species or intermediary reactions. Moreover, a $\mathrm{Cu}-\mathrm{ZnO}$ strong metal-support interaction (SMSI) $)^{9,10}$ was identified as playing a key role in the creation and maintenance of surface $\mathrm{Cu}(\mathrm{I})$ active sites ${ }^{11}$, with the stabilisation of oxygenates near $\mathrm{Cu}(\mathrm{I})$ sites being linked to high $\mathrm{MeOH}$ synthesis activity ${ }^{12}$. Lunkenbein et al. ${ }^{10}$ proposed the formation of a chemically bonded $\mathrm{Cu}^{\delta+}{ }_{-} \mathrm{O}-\mathrm{ZnO}$ interface as the active site for $\mathrm{MeOH}$ synthesis based on their structural/componential observations. To date, the kinetically-relevant formate hydrogenation step still represents one of the major bottlenecks in $\mathrm{MeOH}$ synthesis via the formate-pathway over $\mathrm{ZnO} / \mathrm{Cu}$ catalysts. One promising alternative to intensify the $\mathrm{HCOO}^{*}$-conversion is by resorting to a photo-assisted approach.

Plasmon-induced hot electrons are reported to be capable of activating chemical bonds and driving chemical conversion in a well-designed, energetically-matched surface-adsorbate array ${ }^{13-17}$. For example, Zhang et al. ${ }^{18}$ reported that during $\mathrm{CO}_{2}$ hydrogenation on a $\mathrm{Rh}$ metal surface under irradiation, increased methanation was observed, with $\mathrm{CH}_{4}$ being preferred over the kinetic RWGS product, CO. This effect was attributed to electrons selectively being transferred to the antibonding orbitals of HCO species (weakening of the $\mathrm{C}=\mathrm{O}$ bond). Plasmon-induced $\mathrm{H}_{2}$ dissociation on $\mathrm{Au}^{16}, \mathrm{Ni}^{17}$, and $\mathrm{Al}^{19}$ metals has also been reported and could be effectively employed in photochemical hydrogenation reactions ${ }^{20}$. However, beyond plasmonic enhancement, the potential exists for non-plasmonic components and even further synergism amongst different photo-activation modes; this is an attractive possibility, particularly in complex catalytic systems (where multiple catalyst components and products are involved). For instance, Zhang et al. ${ }^{21}$ recently published findings that demonstrated a synergy between charge separation on an oxide, and localized surface plasmon resonance (LSPR) induced $\mathrm{H}_{2}$ activation on a metal for $\mathrm{CO}_{2}$-to-CO conversion under $\mathrm{UV}$-Vis irradiation.

Recently, Wu et al. ${ }^{22}$ found that light irradiation (UV+visible) can be applied to $\mathrm{MeOH}$ synthesis over $\mathrm{Pd} / \mathrm{ZnO}$ catalysts, with an improvement in product yield by $1.5-3$ times (up to $3.5 \mathrm{mmol}$ $\left.\mathrm{g}_{\text {cat. }}{ }^{-1} \mathrm{~h}^{-1}\right)$, while operating at a lower pressure. Wang et al. ${ }^{23}$ demonstrated that light-assisted $\mathrm{MeOH}$ synthesis $\left(0.06 \mathrm{mmol} \mathrm{g}^{-1}\right.$ $\mathrm{h}^{-1}$ ) can be achieved over defect-rich $\operatorname{In}_{2} \mathrm{O}_{3-\mathrm{x}}(\mathrm{OH})_{\mathrm{y}}$ at atmospheric pressure. The semiconducting $\left(\mathrm{ZnO}, \mathrm{Cu}_{2} \mathrm{O}, \mathrm{CuO}\right)$ and potentially plasmonic $(\mathrm{Cu})$ nature of the industrial $\mathrm{CZA}$ catalyst components suggest that catalytic performance could be improved by simultaneous thermal-light activation. In addition, the excitations associated with specific components of CZA, namely the $\mathrm{ZnO}$ band gap excitation $\left(3.2 \mathrm{eV}^{[22}=\sim 388 \mathrm{~nm}\right)$, and Cu LSPR $\left(\sim 590 \mathrm{~nm}^{24}\right)$, will change the electron-populating state of catalyst, thus regulating the intermediate reactions and product distribution. The effects of band gap excitations associated with $\mathrm{Cu}_{2} \mathrm{O}$ and $\mathrm{CuO}$ components $\left(2.2 \mathrm{eV}\right.$ and $1.7 \mathrm{eV}$, respectively $\left.{ }^{25}\right)$ are negligible due to the very limited presence of these components after reduction $^{26}$.

In this work, we investigate the effect of electronic excitations on photothermal catalytic $\mathrm{CO}_{2}$ hydrogenation over a $\mathrm{Cu} / \mathrm{ZnO}$ / $\mathrm{Al}_{2} \mathrm{O}_{3}$ (CZA) catalyst by probing the surface to explore lighttriggered surface reactions via $\mathrm{X}$-ray spectroscopies and in situ diffuse reflectance infrared Fourier transform spectroscopy (DRIFTS). The key elementary catalytic processes $\left(\mathrm{CO}_{2}\right.$ deoxygenation, $\mathrm{H}_{2}$ dissociation and migration, $\mathrm{HCOO}^{*}$ conversion, etc.) are examined to provide explanation in the variation of catalytic performance and surface chemistry. In addition, the relative role of $\mathrm{Cu}$ and $\mathrm{ZnO}$ sites in $\mathrm{CZA}$-catalysed $\mathrm{MeOH}$ synthesis is also scrutinised.

\section{Results}

Light-assisted $\mathrm{CO}_{2}$ hydrogenation performance. The CZA catalyst comprises spherical copper nanoparticles $(10 \pm 3 \mathrm{~nm})$ surrounded by smaller $\mathrm{ZnO}$ nanoparticles (Fig. $1 \mathrm{a}-\mathrm{c}$ and Supplementary Fig. 2), consistent with the previous reports ${ }^{7,27}$. Further details on the structural properties of CZA-related samples are provided in the Supplementary Information (Supplementary Note 1, Supplementary Figs. 1-5 and Supplementary Table 1). Temperature programmed $\mathrm{CO}_{2}$ hydrogenation was conducted in a Harrick reactor at 21 bar under both dark and irradiated conditions. Catalytic performance was assessed by the $\mathrm{MeOH}$ space time yield (STY) and $\mathrm{MeOH}$ selectivity (Eqs. 1 and 2 in the "Methods" section).

Without light irradiation (thermal catalytic reaction), the lightoff curve for $\mathrm{MeOH}$ STY exhibited a volcano-like profile, which peaked at $275^{\circ} \mathrm{C}\left(245 \mathrm{~g} \mathrm{~kg}_{\text {cat. }}{ }^{-1} \mathrm{~h}^{-1}\right)$. The volcano-like profile is attributed to a steady decrease in $\mathrm{MeOH}$ selectivity from $93 \%$ to $15.3 \%$ as temperature is ramped from $200{ }^{\circ} \mathrm{C}$ to $300{ }^{\circ} \mathrm{C}$. When irradiated with 350-800 nm light, significant photo-enhancement in $\mathrm{MeOH}$ production was only observed at $225^{\circ} \mathrm{C}(32 \%)$, corresponding to the highest $\mathrm{MeOH}$ STY with only a slight change in product selectivity. In addition, compared to the performance at $275^{\circ} \mathrm{C}$ in the dark, $350-800 \mathrm{~nm}$ irradiation enables a $50{ }^{\circ} \mathrm{C}$ decrease in reaction temperature for the same $\mathrm{MeOH}$ yield while simultaneously delivering a much higher selectivity (>75\%) toward MeOH (Fig. 1d, see also Supplementary Note 2). More importantly, the improved $\mathrm{MeOH}$ selectivity suggests that the photo-enhancement is more than a simple heating effect from light irradiation (see also Supplementary Fig. 6 and Supplementary Note 3).

To understand the role of the individual photo-responsive components in the CZA catalyst, isothermal $\mathrm{CO}_{2}$ hydrogenation performance by CZA was assessed at $225^{\circ} \mathrm{C}$. Three different band ranges were employed: $200-500 \mathrm{~nm}, 420-800 \mathrm{~nm}$, and $350-800 \mathrm{~nm}$. The $200-500 \mathrm{~nm}$ spectral range encompassed $\mathrm{ZnO}$ $(3.2 \mathrm{eV})$ band gap excitation while the $420-800 \mathrm{~nm}$ spectral range covered $\mathrm{Cu} / \mathrm{CuO}_{\mathrm{x}}$ (LSPR and band gap excitation, respectively) (Supplementary Fig. 7). Despite the promotion of CO production under all three irradiation conditions (Supplementary Fig. 8a), $\mathrm{MeOH}$ STY was only greatly improved with the irradiation of $350-800 \mathrm{~nm}$ range (Fig. 1e). The findings highlight that simultaneous excitation of both $\mathrm{Cu}$ and $\mathrm{ZnO}$ is crucial to promote synergistic $\mathrm{MeOH}$ production, since of the three band ranges employed, only the $350-800 \mathrm{~nm}$ spectral range encompasses the key excitations of both components. In addition, the cycling result (Fig. 1e) shows that photo-enhanced $\mathrm{MeOH}$ production under $350-800 \mathrm{~nm}$ irradiation can be retained with good durability over 

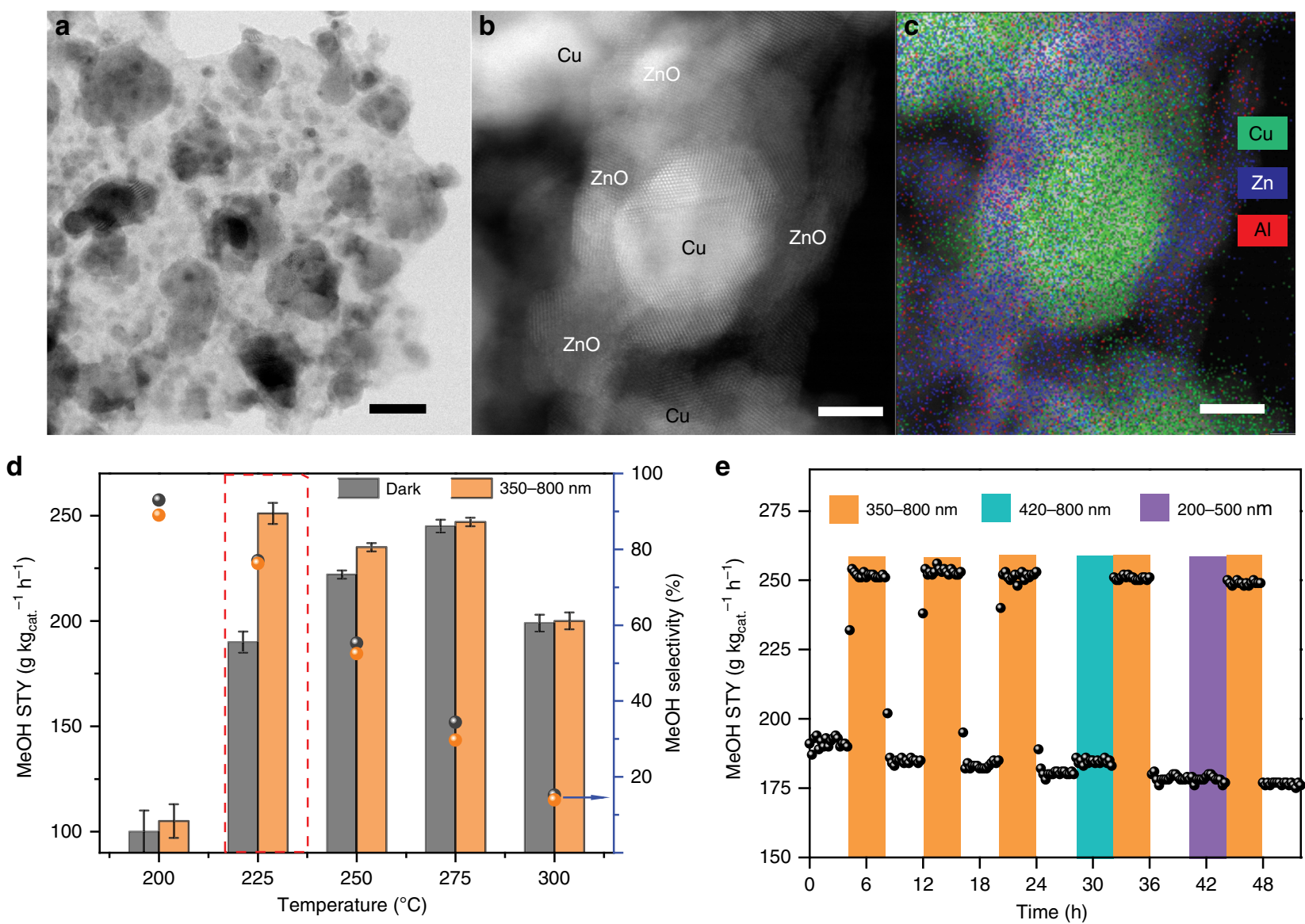

Fig. 1 Structural properties and catalytic activities. a, b HR-TEM images and c EDS map of reduced CZA catalyst, scale bar, $25 \mathrm{~nm}$ (a) and $5 \mathrm{~nm}$ (b, c); d $\mathrm{MeOH}$ selectivity/space time yield (STY) at $200-300{ }^{\circ} \mathrm{C}$ under dark and $350-800$ nm light irradiation (red dotted box indicates the highest photoenhancement at $225^{\circ} \mathrm{C}$ ). Error bars indicate the deviation among three independent experiments; e time-on-stream MeOH yield under different light irradiation conditions (350-800 nm, 200-500 nm, and 420-800 nm, which corresponds to the excitation of Cu, ZnO, and Cu + ZnO, respectively). Reaction conditions: $\mathrm{CO}_{2}: \mathrm{H}_{2}=1: 3.2, \mathrm{GHSV}=8758 \mathrm{~h}^{-1}, \mathrm{P}=21$ bar, $\mathrm{T}=225^{\circ} \mathrm{C}$, light intensity $=600 \mathrm{~mW} \mathrm{~cm}^{-2}$ for all spectral ranges.

$48 \mathrm{~h}$ when light is reintroduced, regardless of the prior lighting conditions.

Surface intermediates and the role of the $\mathrm{Cu}-\mathrm{ZnO}$ interface. To elucidate the role of $\mathrm{Cu}$ and $\mathrm{ZnO}$ in the light-assisted hydrogenation of $\mathrm{CO}_{2}$, surface adsorbed intermediates on $\mathrm{CZA}, \mathrm{Zn}$ / $\mathrm{Al}_{2} \mathrm{O}_{3}$ (ZA), and $\mathrm{Cu} / \mathrm{Al}_{2} \mathrm{O}_{3}$ (CA) were probed using in situ DRIFTS $\left(\mathrm{CO}_{2}+\mathrm{H}_{2}, 50-300^{\circ} \mathrm{C}\right.$ under 15 bar, Fig. 2a, b, and Supplementary Fig. 9). Examination of the DRIFTS spectra of CZA revealed several adsorbed surface species: (i) carbonate $\left(\mathrm{CO}_{3}{ }^{*}, 1463-1492 \mathrm{~cm}^{-1}\right)$, (ii) bicarbonate $\left(\mathrm{HCO}_{3}{ }^{*}, 1622 \mathrm{~cm}^{-1}\right)$, (iii) formate (HCOO*, $1550 \mathrm{~cm}^{-1}$ and $1590 \mathrm{~cm}^{-1}$ ), (iv) methoxy ( $\mathrm{ZnO}-\mathrm{H}_{3} \mathrm{CO}^{*}$ at $1050 \mathrm{~cm}^{-1}$ or $\mathrm{Cu}-\mathrm{H}_{3} \mathrm{CO}^{*}$ at $979 \mathrm{~cm}^{-1}$ ), and, (iv) formaldehyde $\left(\mathrm{H}_{2} \mathrm{CO}^{*}, 1795 \mathrm{~cm}^{-1}\right)^{28}$. Detailed vibrational peak assignments are available in Supplementary Table 2. Notably, different distributions of surface intermediate species were observed on the surface of ZA and CA, supporting our postulation that the two active sites serve different purposes in the synergistic conversion of $\mathrm{CO}_{2}$ to $\mathrm{MeOH}$ (see also Supplementary Note 4).

Bowker and $\mathrm{Waugh}^{29}$ emphasised the importance of the $\mathrm{HCOO}^{*}$ intermediate in $\mathrm{Cu}$ driven $\mathrm{CO}_{2}$ conversion to $\mathrm{MeOH}$. Hence, to distinguish between $\mathrm{HCOO}^{*}$ species adsorbed at different surface sites, herein DRIFTS was performed on catalysts with pre-adsorbed formate species (sodium formate). The DRIFTS spectra (Supplementary Fig. 10) indicate that the $\mathrm{HCOO}^{*}$ vibrational peak at $\sim 1550 \mathrm{~cm}^{-1}$ and $\sim 1590 \mathrm{~cm}^{-1}$ corresponds to $\mathrm{HCOO}^{*}$ on $\mathrm{Cu}\left(\mathrm{Cu}-\mathrm{HCOO}^{*}\right)$ and $\mathrm{Zn}$ $\left(\mathrm{ZnO}-\mathrm{HCOO}^{*}\right)$ respectively. The sole vibrational peak of $\mathrm{ZnO}-\mathrm{HCOO}^{*}$ on CZA suggests that $\mathrm{ZnO}$ is the primary active site for $\mathrm{CO}_{2}$ conversion to formate, and consequently also plays a role in the activation of formate towards subsequent elementary reaction processes. In addition, we observed a similar vibrational feature on $\mathrm{ZA}$ in the range of $1300-1650 \mathrm{~cm}^{-1}$, confirming the preferential initial adsorption of $\mathrm{CO}_{2}$ on the surface of $\mathrm{ZnO}^{30,31}$. The accumulation of $\mathrm{Zn}-\mathrm{HCOO}^{*}$ on $\mathrm{CZA}$ at temperature $<250{ }^{\circ} \mathrm{C}$ suggest that hydrogenation of the formate species represents one of the most significant kinetic barriers in $\mathrm{MeOH}$-synthesis reactions (and is correlated to the observed temperature-dependent photo-enhancement effect described in Supplementary Fig. 11 and Supplementary Note 5). Nonetheless, conversion of $\mathrm{ZnO}-\mathrm{HCOO}^{*}$ to $\mathrm{MeOH}$ is not favourable in the absence of $\mathrm{Cu}$ as suggested by the absence of $\mathrm{H}_{3} \mathrm{CO}^{*}$ species on the surface of ZA (Fig. 2a).

To understand the role of $\mathrm{Cu}$, we compared the DRIFTS spectra of CZA and CA (Fig. 2a). CA exhibits significantly weaker vibrational spectra, predominantly of $\mathrm{Cu}-\mathrm{OH}^{*}\left(1602 \mathrm{~cm}^{-1}\right)$, $\mathrm{Cu}-\mathrm{HCOO}^{*}$ and $\mathrm{Cu}-\mathrm{CO}_{3}{ }^{*}$. Weigel et al. ${ }^{32}$ studied $\mathrm{CO}_{2}$ hydrogenation on $\mathrm{Cu} / \mathrm{ZrO}_{2}$ catalyst and showed that $\mathrm{CO}$ formation may proceed via $\mathrm{CO}_{3}{ }^{*}$ dissociation $\left(\mathrm{CO}_{3}{ }^{*}+\mathrm{H}_{2} \rightarrow\right.$ $\left.\mathrm{CO}_{\text {gas }}+2 \mathrm{OH}^{*}\right)$. This observation is consistent with the surface adsorbed species detected on $\mathrm{CA}$. We consider that the $\mathrm{CO}$ was produced mainly through $\mathrm{CuO}_{\mathrm{x}}-\mathrm{CO}_{3} *$ dissociation at lower 
a

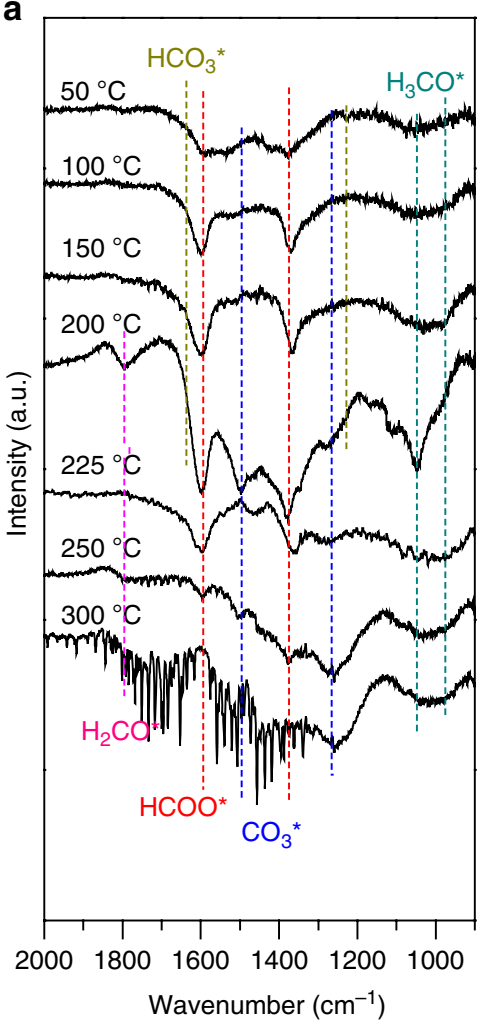

b

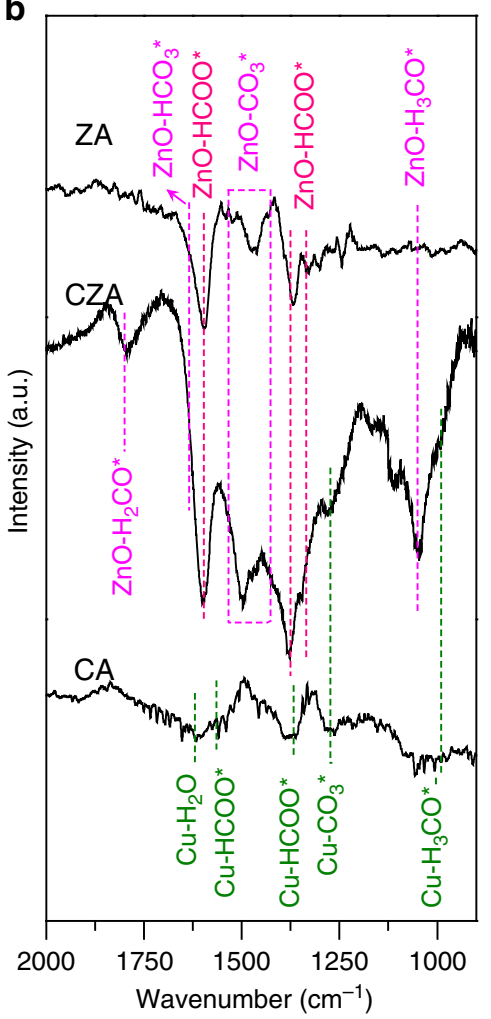

C

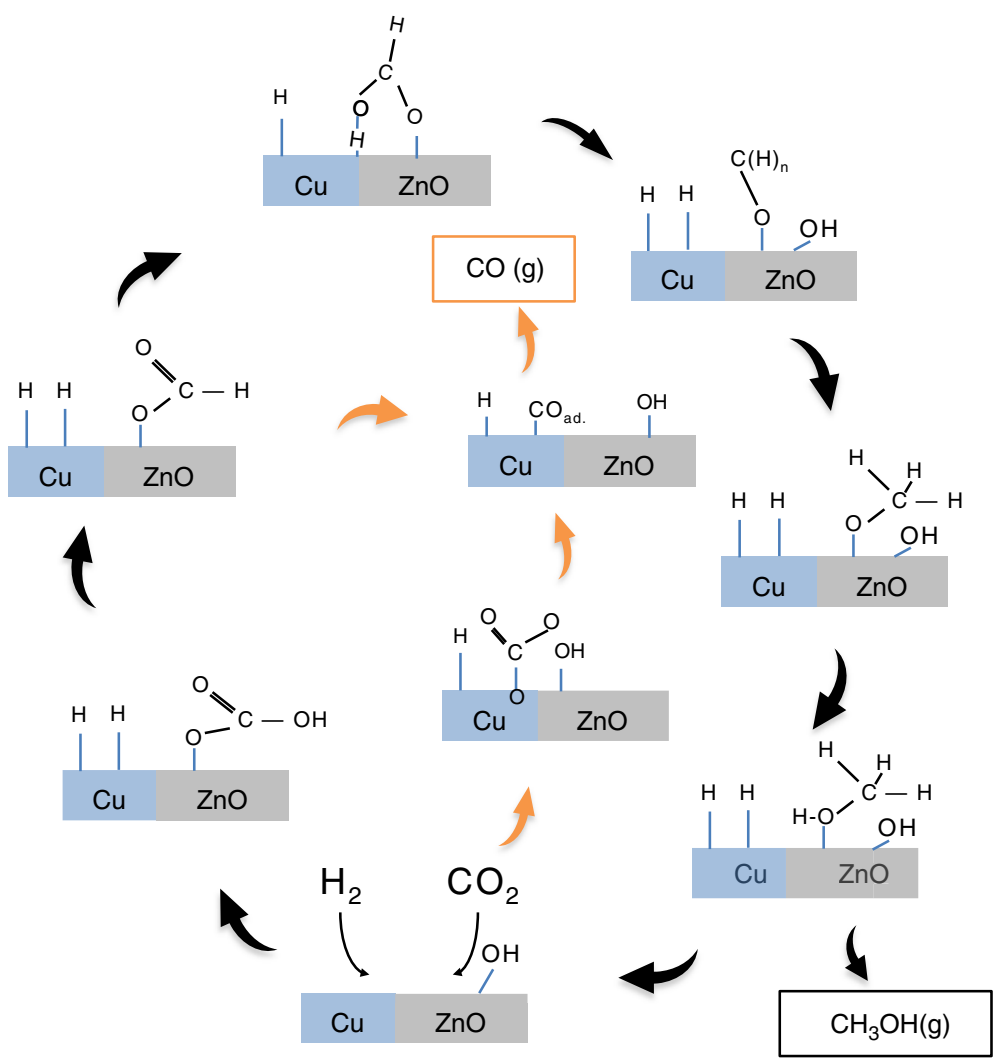

Fig. 2 Surface intermediates and reaction diagram. a Saturated DRIFTS spectra of different samples at $200{ }^{\circ} \mathrm{C}$; $\mathbf{b} \mathrm{N}_{2}$-purged DRIFTS spectra of CZA recorded at different temperatures (when stabilized at each temperature the catalyst was purged under $\mathrm{N}_{2}$ for about $1.5 \mathrm{~h}$ to remove $\mathrm{MeOH}$ and $\mathrm{H}_{2} \mathrm{O}$ molecules), the formaldehyde $\left(\mathrm{H}_{2} \mathrm{CO}{ }^{*}\right)$, formate $\left(\mathrm{HCOO}^{*}\right)$, carbonate $\left(\mathrm{CO}_{3}{ }^{\star}\right)$, bicarbonate $\left(\mathrm{HCO}_{3}{ }^{*}\right)$, and methoxy $\left(\mathrm{H}_{3} \mathrm{CO} \mathrm{O}^{\star}\right)$ species are labelled with dotted lines; c Proposed methanol (black arrow) and $\mathrm{CO}$ production (orange arrow) pathways over $\mathrm{Cu}-\mathrm{ZnO}$ catalyst. 


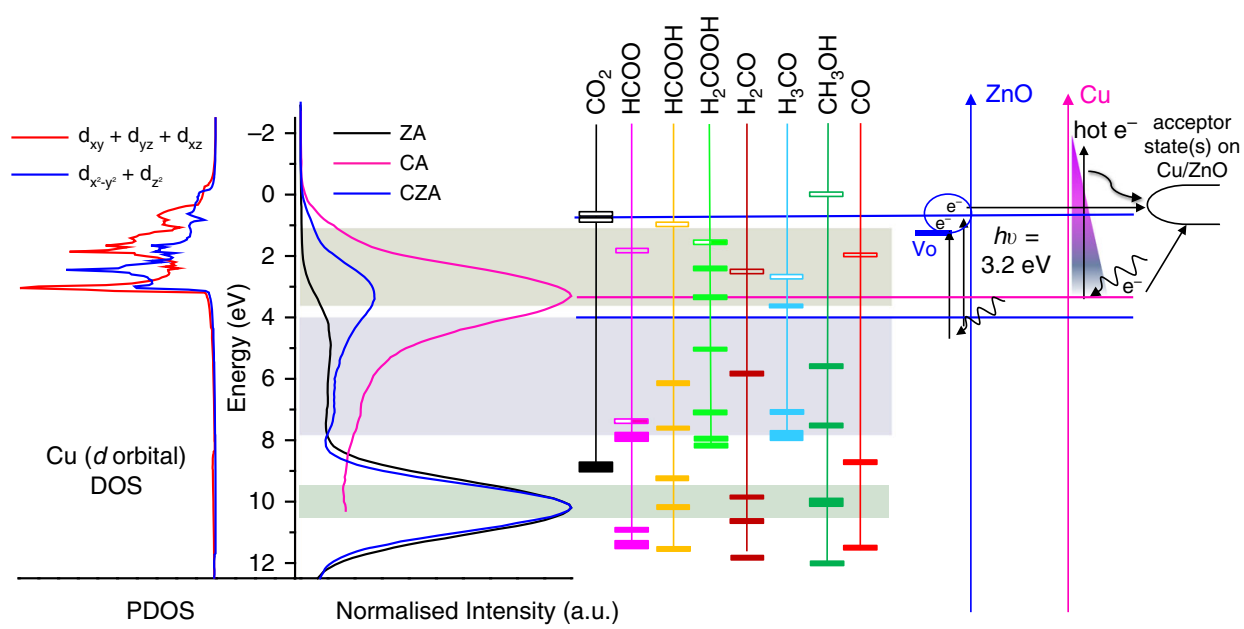

Fig. 3 Alignment of gas phase adsorbate orbital levels. In order to compare the calculated orbital energies with the experimental spectra, the calculated orbital energies were aligned such that all share a common vacuum level. The Fermi levels of Cu $3 d$ DOS and all reaction intermediates are aligned to the CZA Fermi level using a catalyst work function value of $4.7 \mathrm{eV}$, typical of $\mathrm{ZnO}$ and $\mathrm{Al}_{2} \mathrm{O}_{3}$. The aligned orbital levels and the experimental valence band spectra are depicted, hence $E=0 \mathrm{eV}$ corresponds to the CZA Fermi level with the common vacuum level at $-4.7 \mathrm{eV}$ (not shown). The electron-excitation under irradiation and its transfer to surface acceptor states in $\mathrm{ZnO}$ and schematic depiction of LSPR-induced indirect/direct hot electron transfer from Cu to adsorbate.

temperature and was desorbed from the $\mathrm{Cu}$ surface ${ }^{33}$ as indicated by the observation of adsorbed $\mathrm{CO}^{*}$ species $\left(2077 \mathrm{~cm}^{-1}\right.$ and $2094 \mathrm{~cm}^{-1}$ on the $\mathrm{Cu}(111)$ surface $\left.{ }^{34}\right)$ on CZA and CA catalysts (but not on ZA) (Supplementary Fig. 9). Thus, the CA sample exhibits higher selectivity towards CO compared to that of CZA (Supplementary Fig. 8b). Weak $\mathrm{H}_{3} \mathrm{CO}^{*}$ vibrational peaks can be observed on CA $\left(979 \mathrm{~cm}^{-1}\right)$, suggesting that hydrogenation of $\mathrm{HCOO}^{*}$ to $\mathrm{H}_{3} \mathrm{CO}^{*}$ is primarily driven by $\mathrm{Cu}$. However, $\mathrm{ZnO}$ incorporation intensified this process. Additionally, an accelerated decrease in accumulated $\mathrm{HCOO}^{*}$ on CZA compared to ZA (Supplementary Fig. 12) can be observed at $\mathrm{T}>225^{\circ} \mathrm{C}$. These phenomena can be attributed to conversion of the $\mathrm{ZnO}-\mathrm{HCOO}^{*}$ to $\mathrm{H}_{3} \mathrm{CO}^{*}$, presumably at the interfacial perimeter of $\mathrm{Cu}-\mathrm{ZnO}$. Larmier et al. ${ }^{35}$ observed a similar interaction between $\mathrm{Cu}$ metal and $\mathrm{ZrO}_{2}$ support during $\mathrm{CO}_{2}$ conversion to $\mathrm{MeOH}$.

Computational study. It has been proven that for electron transfer to occur between catalyst and adsorbates, orbital overlap between the substrate and adsorbate is essential ${ }^{16,36,37}$. To explore this possibility, first-principles density functional theory (DFT) calculations were performed to obtain the relative orbital energies for each of the identified reactants, products, and intermediates as free gas phase species. These were then compared to the experimental valence band spectra. Despite its limitations (see also Supplementary Note 6), the current method is unbiased and does not make any particular assumption in terms of the surface structure and composition of the catalyst.

The vacant $\mathrm{CO}_{2}$ orbital levels at $0.79 \mathrm{eV}$ and $0.45 \mathrm{eV}$ correspond to the $\mathrm{C}-\mathrm{O} \sigma^{*}$ antibonding orbital and two degenerate $\mathrm{C}-\mathrm{O} \pi^{*}$ antibonding orbitals, respectively. Filling of these orbitals by electron transfer from the substrate is a prerequisite for any degree of chemisorption, and activation towards subsequent reactive processes (i.e. hydrogenation or dissociation). Whilst these levels are lying higher than the main $\mathrm{Cu} 3 d$ valence band, they correspond well with the $\mathrm{ZnO}$ excited state (i.e. the dominant $\mathrm{ZnO} O \mathrm{O}$ p state under UV excitation), or defect-induced states near the Fermi level ${ }^{38}$ when hybridizing with $\mathrm{Cu}$ (Supplementary Fig. 13a). Furthermore, in the CZA catalyst, $\mathrm{Cu}$ LSPR-induced hot electrons could facilitate $\mathrm{CO}_{2}$ activation/dissociation at $\mathrm{Cu}$ surface sites (Fig. 3), accounting for the improved $\mathrm{CO}$-production upon $\mathrm{Cu}$ excitation ( $\mathrm{CO}$ mainly interact with $\mathrm{Cu}$ based on Fig. 3 and DRIFTS results).

Weakening of the $\mathrm{CO}_{2} \mathrm{C}-\mathrm{O}$ bond, proposed to occur as a result of filling of $\mathrm{C}-\mathrm{O}$ antibonding orbitals by electrons from the substrate, could also potentially activate $\mathrm{CO}_{2}$ towards hydrogenation to formate, HCOO*. Examining the DFT-calculated orbital levels for the "formate radical" in Fig. 3 shows the singly occupied orbital associated with the unpaired electron localized on $\mathrm{O}$, which would be associated with binding of the intermediate with the substrate. This orbital level at $7.26 \mathrm{eV}$ overlaps well with the $\mathrm{ZnO}$ valence band, implying preferential adsorption of $\mathrm{HCOO}^{*}$ at $\mathrm{ZnO}$ surface sites. However, the lowest lying fully vacant $\mathrm{HCOO}^{*}$ orbital, corresponding to the $\mathrm{HCOO}^{*} \mathrm{C}-\mathrm{O} \pi^{*}$ antibonding orbital at $1.76 \mathrm{eV}$, overlaps well with the $\mathrm{Cu} 3 d$ band. Any further hydrogenation of the formate intermediate must come at the expense of the $\mathrm{C}=\mathrm{O} \pi$ bond, hence it is possible that filling of the $\mathrm{C}=\mathrm{O} \pi^{*}$ antibonding orbital by electrons originating from the $\mathrm{Cu} 3 d$ band could facilitate formate hydrogenation. This corroborates the DRIFTS results which suggest that $\mathrm{Cu}$ plays a key role in catalyzing this process at the $\mathrm{Cu} / \mathrm{ZnO}$ interface. Subsequent hydrogenation of $\mathrm{HCOO}^{*}$ will lead to the formation of $\mathrm{HCOOH}^{* 8}$. A weak physisorption of $\mathrm{HCOOH}^{*}$ on $\mathrm{Cu}$ surface $\left(\mathrm{BE}_{\mathrm{HCOOH}}=-0.22 \mathrm{eV}\right.$ on $\left.\mathrm{Cu}(111)\right)$, as reported by Grabow et al. ${ }^{39}$, could be implied. However, again in common with $\mathrm{CO}_{2}$, the lowest unoccupied molecular orbital (LUMO) of $\mathrm{HCOOH}^{*}$ $\left(\mathrm{C}=\mathrm{O} \pi^{*}\right.$ antibonding orbital), is well-aligned with the proposed level of the $\mathrm{ZnO}$ dominant excited state under UV excitation. This opens the possibility for activation of the $\mathrm{HCOOH}^{*}$ intermediate by filling the antibonding orbital with electrons originating from excitation of dominant $\mathrm{ZnO} O 2 \mathrm{p}$ states. Accordingly, $\mathrm{HCOO}^{*}$ conversion could be facilitated as the reverse reaction $\mathrm{HCOO}^{*}+\mathrm{H}^{*} \rightarrow \mathrm{HCOOH}^{*}$ is suppressed ${ }^{8}$. Afterwards, an increased interaction between $\mathrm{Cu}$ and $\mathrm{H}_{2} \mathrm{COOH}^{*}$, $\mathrm{H}_{2} \mathrm{CO}^{*}$, and $\mathrm{H}_{3} \mathrm{CO}^{*}$ species are suggested with their first vacant orbitals well-aligned with the $\mathrm{Cu} 3 d$ valence band, thus enabling the further hydrogenation to $\mathrm{MeOH}$ at near- $\mathrm{Cu}$ sites. The result further supports the hypothesis for an interfacial $\mathrm{Cu} / \mathrm{ZnO}$ adsorption site being key to $\mathrm{MeOH}$ synthesis, with different elementary reaction processes being promoted by destabilisation 
of adsorbate bonds by electronic injection into vacant adsorbate antibonding orbitals from states associated with either $\mathrm{ZnO}$ or $\mathrm{Cu}$.

Light-induced $\mathrm{Cu} / \mathrm{ZnO}$ state variations. Under reaction conditions, the $\mathrm{Cu}$ oxidation state is influenced by the varied surface population of $\mathrm{O}^{*}$ and $\mathrm{H}^{*}$ species resulting from $\mathrm{C}-\mathrm{O}$ bond breakage of the $\mathrm{CO}_{2}$ adsorbate and $\mathrm{H}_{2}$ dissociation, respectively. Auger spectroscopy and XPS were conducted to determine the $\mathrm{Cu}$ species distribution of fresh and spent CZA, which were tested under different irradiation conditions (herein referred to as CZA_350-800, CZA_200-500 and CZA_420-800, respectively). The result is shown in Fig. $4 \mathrm{a}$. The dark reaction further reduced $\mathrm{Cu}(\mathrm{II})$ to $\mathrm{Cu}(0)$ (relative to the pre-reduced CZA) while retaining a similar $\mathrm{Cu}(\mathrm{I})$ content. When light was introduced during the reaction, the $\mathrm{Cu}(\mathrm{I})$ was enriched (irrespective of the spectral range) and the $\mathrm{Cu}(\mathrm{I}) / \mathrm{Cu}(0)$ ratio increased accordingly. This observation can be attributed to the promotion of dissociative $\mathrm{CO}_{2}$ chemisorption, leading to the formation of $\mathrm{CO}$ and $\mathrm{Cu}$ oxidation. A relatively lower $\mathrm{Cu}(\mathrm{I}) / \mathrm{Cu}(0)$ value (close to unity) for CZA_420-800 (Supplementary Fig. 14e) could be attributed to the $\mathrm{Cu}$ LSPR-triggered $\mathrm{Cu}-\mathrm{O}$ weakening ${ }^{13}$ together with facilitated $\mathrm{H}_{2}$ dissociation on the $\mathrm{Cu}$ surface ${ }^{40}$, leading to a higher $\mathrm{Cu}$ (0) surface concentration.

The variation in binding energy (BE) for $\mathrm{Zn} 2 \mathrm{p}$ (Fig. $4 \mathrm{~b}$ ) is taken as an indicator of the overall electron exchange in the $\mathrm{ZnO}$ lattice under different reaction conditions. Upon careful inspection, it can be seen that $\mathrm{Zn} 2 \mathrm{p}$ BE of CZA_420-800 is similar to that of reduced catalyst $\left(\mathrm{CZA} \mathrm{H}_{2}\right)$, but lower (by $\sim 0.3 \mathrm{eV}$ ) than that of spent catalysts under dark, under irradiation of $200-500 \mathrm{~nm}$, and under irradiation of $350-800 \mathrm{~nm}$. These indicate that for the latter three reaction conditions, a net electron transfer from $\mathrm{ZnO}$ to $\mathrm{Cu}$ could occur, while under visible light (420-800 nm), the excited $\mathrm{Cu}$ state could inhibit this process.

To gain insights into the local structure of $\mathrm{Cu}$ and $\mathrm{ZnO}, \mathrm{X}$-ray absorption was conducted at the $\mathrm{Cu}$ and $\mathrm{Zn}$ K-edges (Fig. 5, more details in Supplementary Fig. 15) on samples post reaction under differing irradiation conditions. Surprisingly, no sign of $\mathrm{Cu}$ oxide was detected and the X-ray absorption near edge structure
(XANES) region of the X-ray absorption spectra exhibited identical spectroscopic features in all treated samples similar to that of the reference $\mathrm{Cu}$ foil, with a shoulder on the main edge (Feature A at $8981 \mathrm{eV}$ ) and a main absorption peak (Feature B at $8993 \mathrm{eV})^{41}$, which appears to contradict the XPS observations. This could be explained by the difference of detection depth of the two characterization techniques, where XAS is a bulk characterisation technique giving average information for the whole sample and XPS is sensitive to the outermost surface atoms $(<10 \mathrm{~nm})$.

The Zn K-edge XANES spectra indicate that the overall oxidation state of $\mathrm{ZnO}$ in the reduced and spent catalysts did not change compared to the commercial $\mathrm{ZnO}$ reference, as there is no relative shift in the adsorption edge. The $\mathrm{Zn} \mathrm{K}$-edge spectrum is characterized by a main absorption peak (B, $1 \mathrm{~s} \rightarrow \mathrm{Zn} 4 \mathrm{p}-\mathrm{O} 2 \mathrm{p}$ hybridized states) located at $9669 \mathrm{~K} \mathrm{eV}$, a low-energy shoulder (A, $1 \mathrm{~s} \rightarrow \mathrm{Zn} 4 \mathrm{sp}-\mathrm{O} 2 \mathrm{p}$ hybridized states) at $9663 \mathrm{eV}^{41}$. When subtracted with respect to the reduced CZA catalyst (inset of Fig. 5b), we detect an increase in the intensity of feature A, and a decrease in the intensity of main absorption peak B in CZA Dark.

These variations, according to the study of Garcia et al. ${ }^{42}$, could be due to either the change in coordination number or degree of occupation of outer $\mathrm{Zn}$ orbitals (via charge transfer). The former was excluded as the change in $\mathrm{Zn}$ coordination number was negligible in Supplementary Table 3. The change of $\mathrm{Zn}$ electronic states was therefore correlated to the change of states of neighbouring $\mathrm{O}$ atoms. Oxygen defects have been reported as important $\mathrm{CO}_{2}$ anchoring sites under reactive condition. As indicated in O1s spectra of XPS results (Supplementary Fig. 13a and Supplementary Note 7$)$, the oxygen vacancy $\left(\mathrm{O}_{\mathrm{v}}\right)$ variation coincides with the changing pattern of feature A intensity, suggesting that the hybridization of $\mathrm{Zn} 4 \mathrm{sp}-\mathrm{O} 2 \mathrm{p}$ was weakened at oxygen deficient sites. This change is believed to be related to the enhanced supply of $\mathrm{H}^{*}$ from $\mathrm{Cu}$ to $\mathrm{ZnO}$ upon $\mathrm{Cu}$ excitation.

Proposed mechanism. Vibrational spectra and valance band (VB)/DFT results show that, for $\mathrm{MeOH}$ synthesis over the $\mathrm{Cu}$ $\mathrm{ZnO}$ hybrid, a defective $\mathrm{ZnO}$ surface (vacant oxygen sites with trapped electrons ${ }^{43}$, see Supplementary Fig. 13) provides the
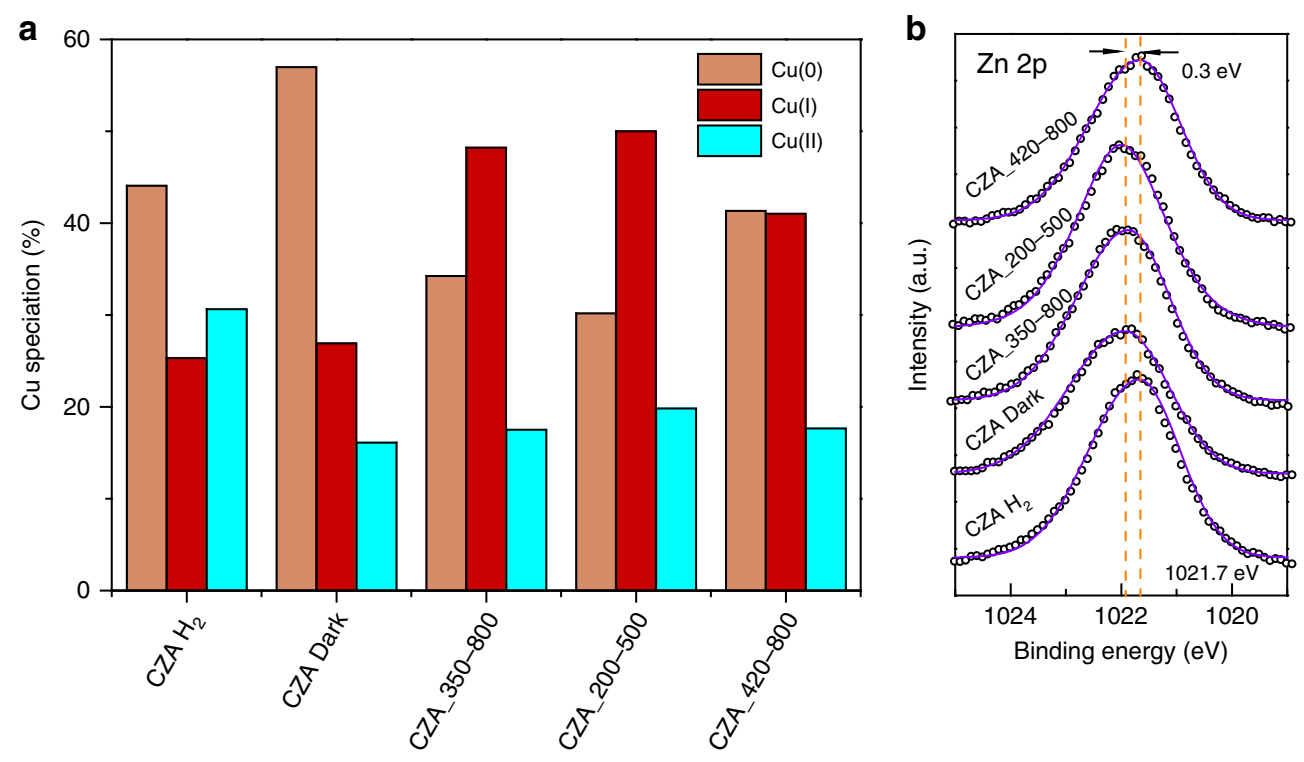

Fig. 4 Copper and zinc states following different conditions. a Cu species distribution for reduced CZA (CZA $\mathrm{H}_{2}$ ) and CZA following reaction under different irradiation conditions (non-illuminated (CZA Dark), illuminated using different spectral range-350-800 nm, 200-500 nm, 420-800 nm). Data extracted from deconvoluted Cu LMM and Cu $2 p$ spectra (see Supplementary Fig. 13 for details); b fitted Zn 2p spectra results for reduced CZA catalyst and spent catalysts under different irradiation conditions. 

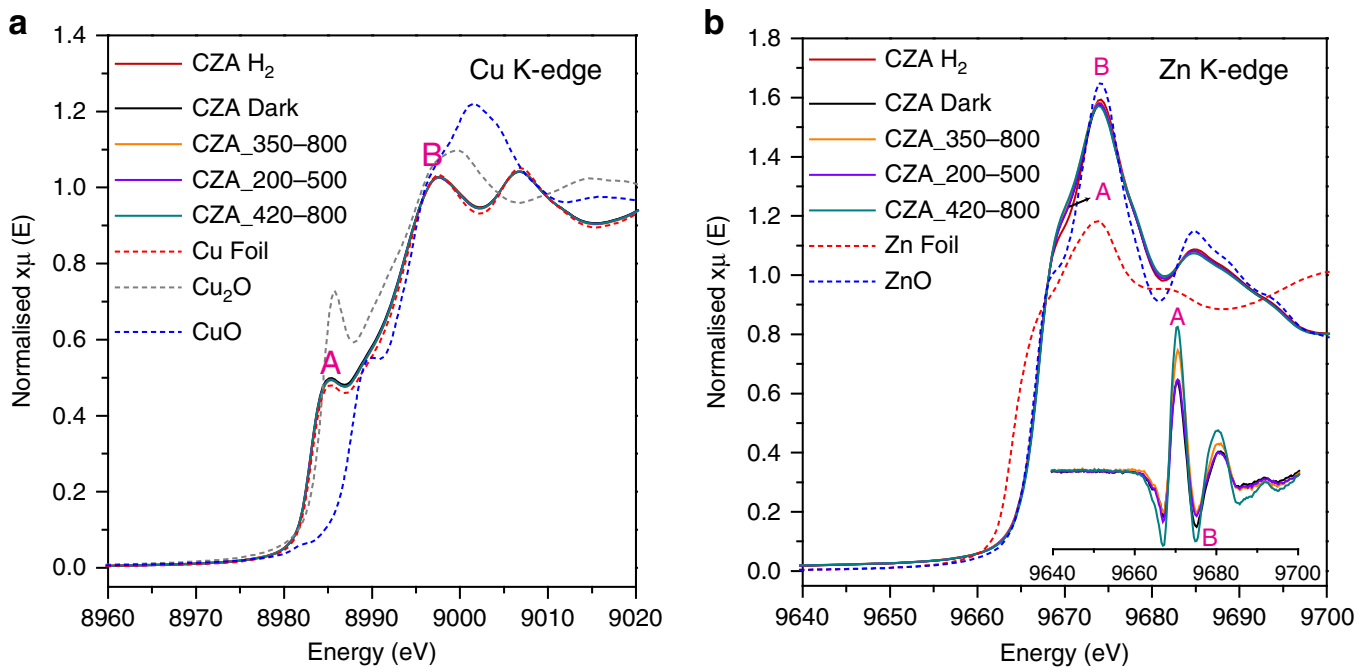

Fig. 5 Local environment of $\mathbf{C u}$ and $\mathbf{Z n O}$ following different conditions. a Cu K-edge and $\mathbf{b} \mathrm{Zn}$ K-edge after reduction and reaction under dark or irradiation with different spectral ranges $(350-800 \mathrm{~nm}, 200-500 \mathrm{~nm}, 420-800 \mathrm{~nm})$. Inset: difference spectra obtained by subtracting the spectrum of reduced catalyst $\left(\mathrm{CZA} \mathrm{H}_{2}\right)$. Feature $\mathrm{A}$ and $\mathrm{B}$ indicate the low-energy shoulder and main absorption peak, respectively, in $\mathrm{Cu}$ and $\mathrm{Zn} \mathrm{K}$ edge.

primary active sites for $\mathrm{CO}_{2}$ chemisorption via the form of $\mathrm{CO}_{3} *$ / $\mathrm{HCO}_{3} * / \mathrm{HCOO}^{*}$ species. Incorporating the $\mathrm{Cu}$ contributes to the subsequent hydrogenation processes, which is attributed to the promotional effect of the $\mathrm{Cu}-\mathrm{ZnO}$ interface and $\mathrm{Cu}$-stimulated $\mathrm{H}^{*}$ supply. The active sites suggested by the molecular orbital energy levels and valence band electronic states for key intermediate species corroborate well with the in situ DRIFTS experiments, providing evidence for the $\mathrm{Cu}-\mathrm{ZnO}$ interfacial sites being the main reaction sites for $\mathrm{MeOH}$ synthesis.

The distinct wavelength-sensitive photo-enhancement is ascribed to product-specific active sites (as also revealed in $\mathrm{MeOH}$ synthesis over the $\mathrm{Pd} / \mathrm{ZnO}$ system ${ }^{44}$ ) on the CZA catalyst where $\mathrm{CO}$ production was photo-accelerated on the $\mathrm{Cu}$ surface with the assistance of electrons generated from $\mathrm{Cu}$ LSPR or $\mathrm{ZnO}$ bandgap excitation. In contrast, $\mathrm{MeOH}$-relevant intermediate reactions were exclusively promoted through dual photoexcitation at the $\mathrm{Cu}-\mathrm{ZnO}$ interfacial perimeter. $\mathrm{HCOO}^{*}$-to$\mathrm{H}_{3} \mathrm{CO}^{*}$ conversion represents the key challenge in promoting $\mathrm{MeOH}$ production over the CZA catalyst from our DRIFTS observation and the theoretical study from Kattel et al. ${ }^{8}$. We concluded that there is a synergy between $\mathrm{Cu}$ and $\mathrm{ZnO}$ for the synthesis of $\mathrm{MeOH}$ under UV-Vis light irradiation. When $\mathrm{Cu}$ alone was excited, the $\mathrm{H}^{*}$ supply could be improved with LSPRinduced $\mathrm{H}_{2}$ cleavage on $\mathrm{Cu}$ and its migration to aid the formate hydrogenation step (reflected by a small increase in $\mathrm{MeOH}$ yield in Fig. 1e). When $\mathrm{ZnO}$ alone was excited, electron transfer to the $\mathrm{Cu}$ was highly favourable so no influence was observed on $\mathrm{MeOH}$ yield. Upon the dual excitation of $\mathrm{Cu}$ and $\mathrm{ZnO}$, net electron transfer from the $\mathrm{ZnO}$ to $\mathrm{Cu}$ was attenuated and both $\mathrm{H}_{2}$ molecules and $\mathrm{HCOO}^{*}$-conversion were stimulated by lightgenerated electrons on the $\mathrm{Cu}$ and $\mathrm{ZnO}$ surfaces, respectively.

Electron excitation and transfer under different irradiation conditions (Fig. 6a, see also Supplementary Note 8) is considered to be the principal driving force for the observed alterations in the $\mathrm{Cu}$ oxidation state, oxygen vacancy levels in $\mathrm{ZnO}$, and $\mathrm{CO}_{2}$ hydrogenation performance. $\mathrm{Cu}-\mathrm{ZnO}$ interplay was promoted during $\mathrm{CO}_{2}$ hydrogenation under dark condition as supported by the HRTEM images (Supplementary Fig. 1) and a positive BE shift in Zn 2p spectra (Fig. 4b). Under 200-500 nm irradiation, the $\mathrm{ZnO}$ excitation could promote electron transfer from the $\mathrm{ZnO}$ to $\mathrm{Cu}$, which contributed to $\mathrm{CO}$ production and resulted in additional $\mathrm{Cu}(\mathrm{I})-\mathrm{O}$ species ( $50 \%$ vs. $28 \%$ in dark) (Eq. (1) in Fig. 6a). Under $420-800 \mathrm{~nm}$ irradiation, only the Cu LSPR was excited; the generated hot electrons could have activated adsorbed $\mathrm{H}_{2}$ molecules, which triggered $\mathrm{Cu}(\mathrm{I})-\mathrm{O}$ reduction (Eq. (2) in Fig. 6a) and oxygen defect creation in $\mathrm{ZnO}$. Regardless, more $\mathrm{Cu}$ (I)-O (40\%) was formed compared to that under the dark condition $(28 \%)$. All of the aforementioned processes are likely to occur under $350-800 \mathrm{~nm}$ irradiation, whereby mediated $\mathrm{Cu}$ (with $\mathrm{Cu}(\mathrm{I})$ ratio of $48 \%$ ) and $\mathrm{ZnO}$ states were finally established after reaching the charge equilibrium state. From XANES observations, we showed that the local electronic structures of $\mathrm{ZnO}$ were also affected by the population of adsorbates (namely $\mathrm{H}^{*}$ ) on the catalyst surface under different reaction conditions. In essence, full spectrum irradiation favours both $\mathrm{H}_{2}$ cleavage $(\mathrm{Cu}$ excitation) and formate conversion ( $\mathrm{ZnO}$ excitation, potentially via facilitating $\mathrm{HCOOH}^{*}$ activation according to Fig. 3), which greatly accelerated $\mathrm{MeOH}$ production (equation (3) in Fig. 6a) as supported by the time-resolved DRIFTS in Supplementary Fig. 16a.

\section{Discussion}

We have studied $\mathrm{CO}_{2}$ hydrogenation by the industrially-relevant CZA catalyst under simultaneous heat and light activation. Notably, $\mathrm{MeOH}$ production was promoted (by $>30 \%$ ) under UVVis irradiation $(350-800 \mathrm{~nm})$. The photothermal catalytic system demonstrated the capability to achieve a more efficient and selective production of $\mathrm{MeOH}$ at a temperature that is $50^{\circ} \mathrm{C}$ lower than that of the thermal catalytic system alone. In contrast, $\mathrm{CO}$ production was boosted under irradiation, irrespective of the spectral range in the present study. Post-reaction structural and electronic properties (XPS and XAS) in conjunction with catalytic reaction mechanistic studies (DRIFTS) suggested that photogenerated electrons and their subsequent interfacial transfer were responsible for the simultaneous transformations in surface chemistry and catalytic reactions. Electrons from either $\mathrm{ZnO}$ band gap excitation (UV irradiation) or $\mathrm{Cu}$ plasmon excitation (visible light irradiation) assisted direct $\mathrm{CO}_{2}$ dissociation to $\mathrm{CO}$ followed by $\mathrm{Cu}(\mathrm{I})-\mathrm{O}$ formation on the $\mathrm{Cu}$ surface. In addition, high energy electrons from the $\mathrm{Cu}$ LSPR facilitated $\mathrm{Cu}(\mathrm{I})-\mathrm{O}$ reduction through improved $\mathrm{H}_{2}$ cleavage on $\mathrm{Cu}$ surface and its migration to $\mathrm{ZnO}$. Upon concurrent excitation of $\mathrm{Cu}$ and $\mathrm{ZnO}$, net electron transfer was attenuated and the sluggish surface reactions-HCOO* hydrogenation and $\mathrm{H}_{2}$ cleavage-were accelerated on the $\mathrm{ZnO}$ and $\mathrm{Cu}$, respectively. This led to 
a

ZnO photo-excitation

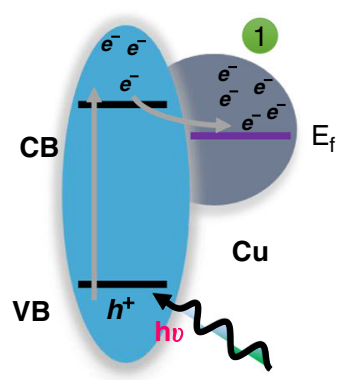

$\mathrm{ZnO}$
Photonic synergism

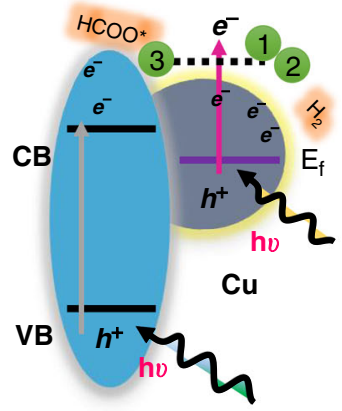

ZnO

\section{Cu photo-excitation}

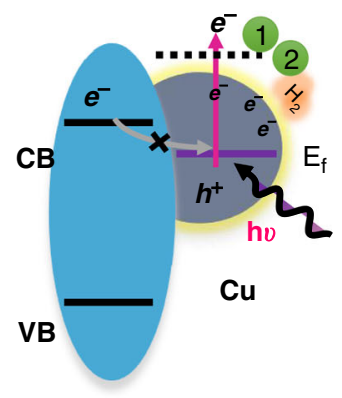

Zno
(1) $\mathrm{Cu}-\mathrm{CO}_{2} \rightarrow \mathrm{CO}(\mathrm{g})+\mathrm{Cu}-\mathrm{O}^{*}$
2
$\mathrm{Cu}-\mathrm{O}^{*}+\mathrm{H}_{2} \rightarrow \mathrm{Cu}(0)+\mathrm{H}_{2} \mathrm{O}$

(3) $\mathrm{CO}_{2}+\mathrm{H}_{2} \rightarrow \mathrm{CH}_{3} \mathrm{OH}$

b

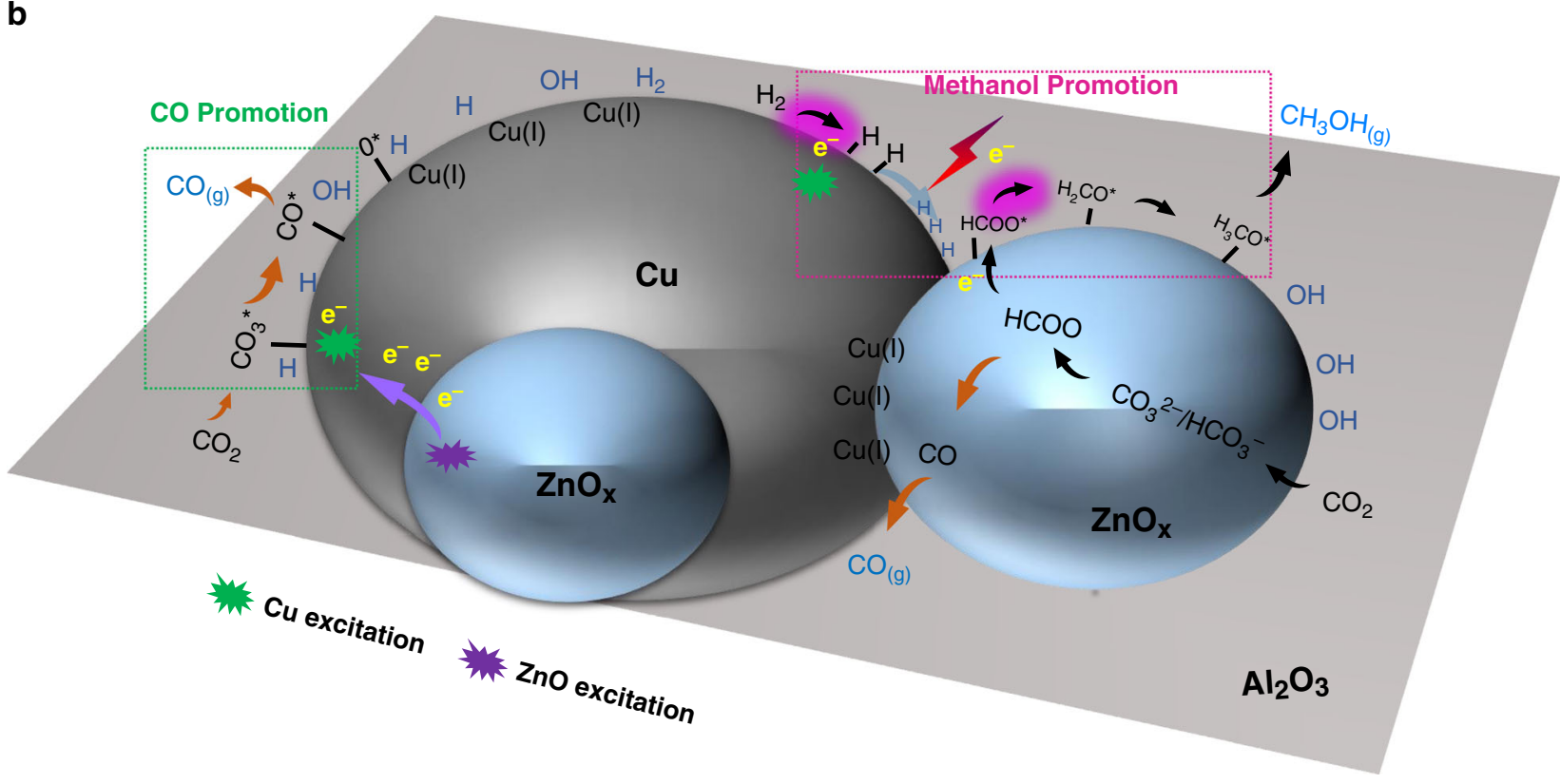

Fig. 6 Proposed light-assisted $\mathrm{CO}_{\mathbf{2}}$ hydrogenation mechanism. a Electron transfer between $\mathrm{Cu}$ and $\mathrm{ZnO}$ under irradiation by different light spectral ranges. The equations below the schematics indicate the potential reactions which could be improved when interacting with certain light-generated electrons. The potential electron acceptors are highlighted. $\mathbf{b}$ The light-aided $\mathrm{CO}_{2}$ hydrogenation reaction over $\mathrm{Cu} / \mathrm{ZnO} / \mathrm{Al}_{2} \mathrm{O}_{3}$ system. Pathways for $\mathrm{CO}$ (chemisorbed $\mathrm{CO}_{2}$ dissociation or $\mathrm{ZnO}-\mathrm{HCOO}^{*}$ decomposition) and methanol production ( $\mathrm{Cu}-\mathrm{ZnO}$ interface mediated processes) are illustrated with black and orange arrows, respectively. A dynamic population of species on $\mathrm{Cu}$ surface $\left(\mathrm{Cu}(\mathrm{I}), \mathrm{H}^{\star}, \mathrm{CO}_{3}{ }^{\star}, \mathrm{CO}^{\star}\right), \mathrm{ZnO}$ surface $\left(\mathrm{OH}^{\star}, \mathrm{CO}_{3}{ }^{*} / \mathrm{HCO}_{3}{ }^{*}, \mathrm{HCOO}^{\star}\right)$ and $\mathrm{Cu}-\mathrm{ZnO}$ interface perimeter $\left(\mathrm{HCOO}^{*}, \mathrm{H}_{2} \mathrm{CO}, \mathrm{H}_{3} \mathrm{CO}^{*}\right.$ ) under reactive condition are envisioned. The electrons transferred to $\mathrm{Cu}$ surface promote $\mathrm{CO}_{2}$ dissociation to $\mathrm{CO}$ (green dotted rectangle), while the light-mediated methanol production is attributed to the promoted $\mathrm{H}^{\star}$-supply and $\mathrm{HCOO}^{\star}$ hydrogenation (glowing dark arrow) at the $\mathrm{Cu}-\mathrm{ZnO}$ interface perimeter (red dotted rectangle) under dual excitation of $\mathrm{Cu}$ and $\mathrm{ZnO}$.

enhanced $\mathrm{MeOH}$ production at the $\mathrm{Cu}-\mathrm{ZnO}$ interfacial perimeter. The study illustrates the synergy between pivotal adsorbed intermediate species (e.g., $\mathrm{HCOO}^{*}, \mathrm{H}^{*}$ ) at the interfacial perimeter of $\mathrm{Cu}-\mathrm{ZnO}$, and provides understanding on the light-heat synergism in site-specific catalytic systems; more generally it gives insight into the relative roles of $\mathrm{ZnO}$ and $\mathrm{Cu}$ in $\mathrm{Cu} / \mathrm{ZnO}$ catalysed $\mathrm{MeOH}$ synthesis.

\section{Methods}

Materials. Chemicals were used as supplied: copper (II) nitrate $\left(\mathrm{Cu}\left(\mathrm{NO}_{3}\right)_{2} \cdot 3 \mathrm{H}_{2} \mathrm{O}\right.$, Sigma-Aldrich); zinc nitrate $\left(\mathrm{Zn}\left(\mathrm{NO}_{3}\right)_{2} \cdot 6 \mathrm{H}_{2} \mathrm{O}\right.$, Sigma-Aldrich); aluminium nitrate $\left(\mathrm{Al}\left(\mathrm{NO}_{3}\right)_{3} .9 \mathrm{H}_{2} \mathrm{O}\right.$, Sigma-Aldrich); sodium carbonate $\left(\mathrm{Na}_{2} \mathrm{CO}_{3}\right.$, Sigma-Aldrich)

Catalyst synthesis. All metal oxides were prepared via a conventional coprecipitation method. Typically, $14 \mathrm{ml} 0.5 \mathrm{M} \mathrm{Cu}\left(\mathrm{NO}_{3}\right)_{2}, 4 \mathrm{ml} 0.5 \mathrm{M} \mathrm{Zn}\left(\mathrm{NO}_{3}\right)_{2}$, and $2 \mathrm{ml} 0.5 \mathrm{M} \mathrm{Al}\left(\mathrm{NO}_{3}\right)_{3}$ were added to a $50 \mathrm{ml}$ beaker to give a mixed solution with a molar ratio of $\mathrm{Cu}: \mathrm{Zn}: \mathrm{Al}=7: 2: 1$. After stirring at $65^{\circ} \mathrm{C}$ for $20 \mathrm{~min}$ in an oil bath,
$10 \mathrm{ml} 1.2 \mathrm{M} \mathrm{Na}_{2} \mathrm{CO}_{3}$ solution was added dropwise as the precipitant with the solution then stirred for another $10 \mathrm{mins}$. The precipitates were aged ( $>60 \mathrm{~min}$ ), washed, filtered and dried overnight $\left(>80^{\circ} \mathrm{C}\right)$. The obtained precursor was ground and calcined at $250^{\circ} \mathrm{C}$ for $3 \mathrm{~h}\left(5^{\circ} \mathrm{C} \mathrm{min}{ }^{-1}\right.$ ramping rate, $30 \mathrm{ml} \mathrm{min}^{-1}$ air flow). Reduction was conducted either in a tube furnace (ex situ at $250{ }^{\circ} \mathrm{C}$ for $3 \mathrm{~h}$ under $10 \% \mathrm{H}_{2} / \mathrm{N}_{2}$ ) or a Harrick reactor (in situ at $350^{\circ} \mathrm{C}$ for $1 \mathrm{~h}$ under $10 \mathrm{ml} \mathrm{min}{ }^{-1} \mathrm{H}_{2}$ ). The reduced $\mathrm{Cu} / \mathrm{ZnO} / \mathrm{Al}_{2} \mathrm{O}_{3}$ catalyst is denoted as CZA. Catalysts containing $\mathrm{Cu}+\mathrm{Al}, \mathrm{Cu}+\mathrm{Zn}$, and $\mathrm{Zn}+\mathrm{Al}$ were synthesised using the same procedure and the same metal ratio (Cu: $\mathrm{Zn}: \mathrm{Al}=7: 0: 1,7: 2: 0$, and $0: 2: 1$, respectively) as controls. The reduced $\mathrm{Cu} / \mathrm{Al}_{2} \mathrm{O}_{3}, \mathrm{Cu} / \mathrm{ZnO}$, and $\mathrm{ZnO} / \mathrm{Al}_{2} \mathrm{O}_{3}$ catalysts are denoted as $\mathrm{CA}, \mathrm{CZ}$, and $\mathrm{ZA}$, respectively.

Catalyst characterisation. High angle annular dark field-scanning transmission electron microscopy (HAADF-STEM) and Energy Dispersive X-ray (EDX) spectroscopy of the CZA and spent CZA catalysts were conducted on a JEOL JEMARM200F operating at $200 \mathrm{kV}$. The crystal phase of the prepared catalysts was analysed using a PANalytical Xpert Multipurpose X-ray Diffraction (XRD) System. UV-Vis spectra were recorded with a Shimadzu UV-3600 UV-Vis-NIR Spectrophotometer using $\mathrm{BaSO}_{4}$ as the reference. $\mathrm{Cu}$ dispersion, temperature-programmed 
$\mathrm{H}_{2}$ reduction $\left(\mathrm{H}_{2}\right.$-TPR), and temperature-programmed $\mathrm{CO}_{2}$ desorption $\left(\mathrm{CO}_{2}\right.$ TPD) were conducted on an AutoChem II 2920 system. For Cu dispersion analysis, $\mathrm{Cu}$ oxide was first reduced to $\mathrm{Cu}$ metal in a gas flow mixture of $10 \% \mathrm{H}_{2}-\mathrm{Ar}$ (ramping temperature to $673{ }^{\circ} \mathrm{C}$ at $10^{\circ} \mathrm{C} \mathrm{min}^{-1}$ ) during first $\mathrm{H}_{2}$-TPR test. Then purged with $\mathrm{Ar}$ for $1 \mathrm{~h}$ after cooling to $50^{\circ} \mathrm{C}$. Oxidation of $\mathrm{Cu}$ to $\mathrm{Cu}_{2} \mathrm{O}$ was assessed by $\mathrm{N}_{2} \mathrm{O}$ treatment $\left(\right.$ at $50^{\circ} \mathrm{C}$ ) with a second $\mathrm{H}_{2}$-TPR on the formed $\mathrm{Cu}_{2} \mathrm{O}$ then conducted (same procedure with first $\mathrm{H}_{2}$-TPR applied). $\mathrm{Cu}$ dispersion was derived from the $\mathrm{H}_{2}$ uptake $(Q)$ in two TPR curves: $\mathrm{Cu}$ dispersion $=2 Q$ ( $\left.2^{\text {nd }} \mathrm{TPR}\right) /$ $Q\left(1^{\text {st }}\right.$ TPR $)$.

XAFS measurements were performed on the B18 beamline at the Diamond Light Source, Didcot, UK. Measurements were performed in transmission mode using a QEXAFS setup with fast-scanning $\mathrm{Si}$ (111) double crystal monochromator. XAFS spectra were acquired in $60 \mathrm{~s}$ and averaged over 3 scans, concurrently with the appropriate foil as reference and for simultaneous reference data collection. The spent catalysts were scanned at the $\mathrm{Cu} \mathrm{K}$ edge $(\mathrm{kmax}=12 \AA)$ and $\mathrm{Zn} \mathrm{K}$ edge $(\mathrm{kmax}=9.5 \AA)$. The kmax for $\mathrm{Zn} \mathrm{K}$ edge was reduced due to the close proximity of the $\mathrm{Cu} \mathrm{K}$ edge. Samples of spent catalysts were sealed in the Harrick DRIFTS cell under Ar post reaction with the use of isolation valves and were placed into a glove box for sample protection. No samples were exposed to air during the entire course of sample analysis to avoid sample oxidation from atmospheric oxygen. All spent catalysts were purged with $\mathrm{Ar}$ for $10 \mathrm{~min}$ during the cooling phase after $3 \mathrm{~h}$ of reaction ( $3 \mathrm{~h}$ of dark reaction or $1 \mathrm{~h}$ of dark reaction with $2 \mathrm{~h}$ of light irradiation) and were transferred out of the reactor immediately into the glove box once the reactor reached room temperature (typically within $10 \mathrm{~min}$ of Ar flow). Spent catalysts were mixed with an appropriate amount of cellulose for dilution and were made into pellets and sealed in an Ar-contained gas cell for XAFS measurements. XAFS data was processed using Athena and Artemis software within the Demeter package.

XPS measurements were performed with a Kratos Axis Supra equipped with an $\mathrm{Al} \mathrm{Ka}$ source $(1486.68 \mathrm{eV}, 150 \mathrm{~W}, 10 \mathrm{~mA} \times 15 \mathrm{kV})$. All XPS spectra were normalised to the $\mathrm{C} 1 \mathrm{~s}$ peak $=285.0 \mathrm{eV}$ for adventitious carbon. The spent catalysts samples were treated the same way as for XAFS measurements (without exposure to air), without dilution with cellulose and pelleting. Data analysis was performed using the Avantage software. A smart-Shirley background was applied to all spectra.

Photothermal $\mathrm{CO}_{\mathbf{2}}$ hydrogenation. Photothermal $\mathrm{CO}_{2}$ hydrogenation experiments were performed using a Harrick flow reactor system at varying pressures (1-21 bar) as shown in Supplementary Fig. 17. The reactor system comprised: (i) a LX300F Xe illuminator (Perkin Elmer/ILC Technologies) mounted in an Eagle R300-3J lamp housing; and (ii) a stainless-steel Harrick reactor (HVC-MRA-5, Harrick's Scientific, USA) with $13 \times 2 \mathrm{~mm} \mathrm{SiO}_{2}$ window for irradiation from above and compensatory heating from below (heating cartridge and K-type thermocouple). The light source was placed $6 \mathrm{~cm}$ above the reactor window and was directed towards the reactor with a MR 60/90 light reflection unit. Additional control of the spectral region of light incident upon the reactor was provided by optional cold mirrors (range of $200-500 \mathrm{~nm}$ or $350-800 \mathrm{~nm}$ ) and/or a Schott GG420 long pass glass filter (visible light irradiation, $>420 \mathrm{~nm}$ ). The intensity of the light source was governed by the current output. The intensity of the different light sources incident upon the catalyst bed was controlled to be around $600 \mathrm{mV} \mathrm{cm}^{-2}$ (measured with a reference silicon solar cell and light intensity meter). The reactor temperature was controlled by a thermocouple and heating system connected to the Harrick reactor under both dark and light experiments. Prior to reaction, $30 \mathrm{mg}$ of catalyst was reduced in situ at $350^{\circ} \mathrm{C}\left(\right.$ ramp rate $\left.5^{\circ} \mathrm{C} \mathrm{min}-1\right)$ for $1 \mathrm{~h}$ under a $10 \mathrm{~mL} \mathrm{~min}^{-1}$ hydrogen flow. Subsequently, $\mathrm{CO}_{2}$ hydrogenation from 200 to $400^{\circ} \mathrm{C}$ was performed with $\mathrm{H}_{2}+\mathrm{CO}_{2}$ (with a ratio of $\mathrm{H}_{2}$ : $\mathrm{CO}_{2}=3.2: 1$ ) feedstock (flow rate $=20 \mathrm{~mL} \mathrm{~min}^{-1}$ ). At each temperature step, gas samples were collected after $>30 \mathrm{~min}$ to allow the reaction to reach steady state. Samples from the reactor outlet were injected into a gas chromatograph (Shimadzu GC2010-Plus) equipped with a thermal conductivity detector (TCD) and flame ionization detector (FID), and a mass spectrometer to help identify the products. The stainless-steel gas line between the reactor and GC system was heated $\left(\right.$ at $\left.130^{\circ} \mathrm{C}\right)$ to avoid the condensation of the liquid products. Only $\mathrm{CO}$ and $\mathrm{MeOH}$ were detected as the products over CZA catalyst (methane production detected in vibrational spectra is below the detection limit of $\mathrm{GC}$ ), the $\mathrm{MeOH}$ production performance was evaluated with $\mathrm{MeOH}$ space time yield (MeOH STY) and $\mathrm{MeOH}$ selectivity (Eqs. 1 and 2 , respectively):

$$
\begin{gathered}
\mathrm{MeOH} / \mathrm{CO} \text { STY }=\frac{F_{\text {tot. }} \times R_{\mathrm{CO} / \mathrm{MeOH}} \times 10^{-3} \times 60}{V_{\mathrm{m}} \times m_{\text {cat. }} \times 10^{-5}} \\
\mathrm{MeOH} \text { selectivity }=\frac{\text { MeOH STY }}{\mathrm{MeOH} \mathrm{STY}+\mathrm{COSTY}}
\end{gathered}
$$

where, $F_{\text {tot. }}\left(\mathrm{ml} \mathrm{min}^{-1}\right)$ is the total flow rate of outlet gas, $R_{\mathrm{CO} / \mathrm{MeOH}}(\%)$ is volume/ flow ratio of $\mathrm{MeOH} / \mathrm{CO}$ product calculated from TCD/FID peak signal using calibrated peak area-flow ratio relation curve. $V_{\mathrm{m}}\left(\mathrm{L} \mathrm{mol}^{-1}\right)$ is the molar volume of gases. $m_{\text {cat. }}(\mathrm{mg})$ is the mass of catalyst $(30 \mathrm{mg})$.

In situ diffuse reflectance infrared Fourier transformed spectroscopy. In situ DRIFTS was performed using a Brüker VERTEX 70v FTIR spectrometer equipped with a liquid $\mathrm{N}_{2}$-cooled MIR source, $\mathrm{KBr}$ optics, and a RockSolid interferometer.
The home-made DRIFTS set-up, including the provision of in situ irradiation $(350-800 \mathrm{~nm})$ during analysis, is depicted in Supplementary Fig. 18. To maintain consistency, irradiation of the DRIFTS sample was conducted using a Xe lamp as the light source and a $\varnothing 4 \mathrm{~mm}$ aluminium reflective collimator was installed inside the DRIFTS chamber. A $2 \mathrm{~m}$ custom made patch cable with $\varnothing 1000 \mu \mathrm{m}, 0.50$ numerical aperture, high hydroxide $(\mathrm{OH})$, core step-index multimode fibre terminated by Sub-Miniature version A (SMA) mating sleeves was used to connect the Xe lamp (adapter used) and the collimator. For each analysis, $\sim 30 \mathrm{mg}$ of (diamond-diluted) catalyst (10 wt.\% of catalyst) was placed in a commercial in situ DRIFTS cell [HVC-DRM-5, Harrick's Scientific, USA] possessing ZnSe windows and equipped with an ohmic heating device. Cu-containing samples (CZA, CA) were diluted with inert diamond for receiving an ample reflectance signal amplitude (pure reduced $\mathrm{Cu}$ samples are black), then pre-treated by calcining at $400^{\circ} \mathrm{C}$ in air to remove residual organic species, followed by in situ reduction in a Harrick ${ }^{\circledast}$ reaction cell at $350^{\circ} \mathrm{C}$ in pure $\mathrm{H}_{2}$ (flow rate $=20 \mathrm{~mL} \mathrm{~min}^{-1}$ ) for $1 \mathrm{~h}$. After cooling to $50^{\circ} \mathrm{C}$ under $\mathrm{N}_{2}$, the system was pressurized to 15 bar with an elevated $\mathrm{N}_{2}$ flow rate $\left(5-15 \mathrm{ml} \mathrm{min}^{-1}\right)$ (in which the spectrum was taken as a background). In situ DRIFTS analysis was then performed for temperature programmed $\mathrm{CO}_{2}$ hydrogenation from $50-300^{\circ} \mathrm{C}$ with a 3:1 ratio of $\mathrm{H}_{2}: \mathrm{CO}_{2}$ feedstock (total flow rate $\left.=8 \mathrm{~mL} \mathrm{~min}^{-1}\right)$. At each temperature step, the steady-state spectra and purged spectra $\left(\mathrm{N}_{2}\right.$ purging for $\left.1.5 \mathrm{~h}\right)$ were both recorded with 64 scans at $1 \mathrm{~cm}^{-1}$ resolution in the range of $600-4000 \mathrm{~cm}^{-1}$. For the light-assisted reaction, Xe lamp irradiation was directed into the reactor using the optic fibre and collimator (see scheme S2).

Computational details. Gaussian $16 \operatorname{code}^{45}$ was used for the calculation of orbital energy of free gas phase reactant, product and species. The PBE exchange-correlation functional was used throughout ${ }^{46}$, and a split-valence triple- $\zeta$ quality Pople basis set was applied, with a single polarisation function included $\left(6-311 \mathrm{G}^{*}\right)^{47,48}$. DFT calculations were performed for each of the free gas phase reactant, product and intermediate species using the Gaussian 16 code All structures were optimised such that all forces on atoms were converged to within $0.0003 E_{\mathrm{h}} / a_{0}$. The PBE exchange-correlation functional was used throughout, and a split-valence triple- $\zeta$ quality Pople basis set was applied, with a single polarisation function included $\left(6-311 \mathrm{G}^{*}\right)$. Details can be found in supporting information.

In order to afford comparison with the CZA VB spectra, the calculated projected density of states (PDOS) is presented for bulk $\mathrm{Cu}$ in Fig. 3. Plane-wave DFT as implemented in the VASP v5.4.4 code ${ }^{49,50}$ using a plane-wave cut-off of $450 \mathrm{eV}$ and the $\mathrm{PBE}^{46}$ exchange-correlation functional. Optimisation of the bulk FCC $\mathrm{Cu}$ lattice parameter was performed by fitting to the Birch-Murnaghan equation of state before performing the PDOS calculation, obtaining a lattice parameter of $3.63 \mathrm{~A}$ for a cubic close packed periodically repeating cell consisting of four $\mathrm{Cu}$ atoms. The Monkhorst-Pack k-point sampling scheme ${ }^{51}$ was applied, using a dense $24 \times 24 \times 24 \mathrm{k}$-point sampling mesh to enable accurate calculation of the PDOS.

\section{Data availability}

The data that support the plots in this paper and the other findings of this study are available from the corresponding authors on reasonable request.

Received: 11 November 2019; Accepted: 26 February 2020; Published online: 31 March 2020

\section{References}

1. Olah, G. A. Beyond oil and gas: the methanol economy. Angew. Chem. Int. Ed. 44, 2636-2639 (2005)

2. Tackett B. M., Gomez E., Chen J. G. Net reduction of $\mathrm{CO}_{2}$ via its thermocatalytic and electrocatalytic transformation reactions in standard and hybrid processes. Nat. Catal. 2, 381-386 (2019).

3. Tountas, A. A. et al. Towards solar methanol: past, present, and future. $A d v$. Sci. 6, 1801903 (2019)

4. Artz, J. et al. Sustainable conversion of carbon dioxide: an integrated review of catalysis and life cycle assessment. Chem. Rev. 118, 434-504 (2018).

5. Porosoff, M. D., Yan, B. \& Chen, J. G. Catalytic reduction of $\mathrm{CO}_{2}$ by $\mathrm{H}_{2}$ for synthesis of $\mathrm{CO}$, methanol and hydrocarbons: challenges and opportunities. Energy Environ. Sci. 9, 62-73 (2016).

6. Martin, O. et al. Zinc-rich copper catalysts promoted by gold for methanol synthesis. ACS Catal. 5, 5607-5616 (2015)

7. Behrens, M. \& Schlögl, R. How to prepare a good $\mathrm{Cu} / \mathrm{ZnO}$ catalyst or the role of solid state chemistry for the synthesis of nanostructured catalysts. Z. anorg. allg. Chem. 639, 2683-2695 (2013).

8. Kattel, S., Ramírez, P. J., Chen, J. G., Rodriguez, J. A. \& Liu, P. Active sites for $\mathrm{CO}_{2}$ hydrogenation to methanol on $\mathrm{Cu} / \mathrm{ZnO}$ catalysts. Science 355, 1296-1299 (2017). 
9. Nakamura, J., Choi, Y. \& Fujitani, T. On the issue of the active site and the role of $\mathrm{ZnO}$ in $\mathrm{Cu} / \mathrm{ZnO}$ methanol synthesis. Catalysts. Top. Catal. 22, 277-285 (2003).

10. Lunkenbein, T. et al. Bridging the time gap: a copper/zinc oxide/aluminum oxide catalyst for methanol synthesis studied under industrially relevant conditions and time scales. Angew. Chem. 128, 12900-12904 (2016).

11. Yasuo, I. \& Hiroyasu, N. Site-selective X-ray absorption fine structure (XAFS) spectroscopy (2). XAFS spectra tuned to surface active sites of $\mathrm{Cu} / \mathrm{ZnO}$ and $\mathrm{Cr} / \mathrm{SiO}_{2}$ catalysts. Bull. Chem. Soc. Jpn. 73, 1581-1587 (2000).

12. Fujitani, T. et al. The role of metal oxides in promoting a copper catalyst for methanol synthesis. Catal. Lett. 25, 271-276 (1994).

13. Marimuthu, A., Zhang, J. \& Linic, S. Tuning selectivity in propylene epoxidation by plasmon mediated photo-switching of $\mathrm{Cu}$ oxidation state. Science 339, 1590-1593 (2013).

14. Tan, T. H. et al. Plasmon enhanced selective electronic pathways in $\mathrm{TiO}_{2}$ supported atomically ordered bimetallic Au-Cu alloys. J. Catal. 352, 638-648 (2017).

15. Song, H. et al. Light-enhanced carbon dioxide activation and conversion by effective plasmonic coupling effect of Pt and Au nanoparticles. ACS Appl. Mater. Interfaces 10, 408-416 (2018).

16. Mukherjee, S. et al. Hot electrons do the impossible: plasmon-induced dissociation of $\mathrm{H}_{2}$ on Au. Nano Lett. 13, 240-247 (2013).

17. Sastre, F., Puga, A. V., Liu, L., Corma, A. \& García, H. Complete photocatalytic reduction of $\mathrm{CO}_{2}$ to methane by $\mathrm{H}_{2}$ under solar light irradiation. J. Am. Chem. Soc. 136, 6798-6801 (2014).

18. Zhang, X. et al. Product selectivity in plasmonic photocatalysis for carbon dioxide hydrogenation. Nat. Commun. 8, 14542 (2017).

19. Zhou, L. et al. Aluminum nanocrystals as a plasmonic photocatalyst for hydrogen dissociation. Nano Lett. 16, 1478-1484 (2016).

20. Aslam, U., Rao, V. G., Chavez, S. \& Linic, S. Catalytic conversion of solar to chemical energy on plasmonic metal nanostructures. Nat. Catal. 1, 656 (2018).

21. Zhang, H., Itoi, T., Konishi, T. \& Izumi, Y. Dual photocatalytic roles of light: charge separation at the band gap and heat via localized surface plasmon resonance to convert $\mathrm{CO}_{2}$ into $\mathrm{CO}$ over silver-zirconium oxide. J. Am. Chem. Soc. 141, 6292-6301 (2019).

22. Wu D. et al. Plasmon-assisted photothermal catalysis of low-pressure $\mathrm{CO}_{2}$ hydrogenation to methanol over $\mathrm{Pd} / \mathrm{ZnO}$ catalyst. ChemCatChem. https://doi. org/10.1002/cctc.201802081 (2019).

23. Wang, L. et al. Photocatalytic hydrogenation of carbon dioxide with high selectivity to methanol at atmospheric pressure. Joule 2, 1369-1381 (2018).

24. Meng, X. et al. Nanometals for solar-to-chemical energy conversion: from semiconductor-based photocatalysis to plasmon-mediated photocatalysis and photo-thermocatalysis. Adv. Mater. 28, 6781-6803 (2016).

25. Li, H., Su, Z., Hu, S. \& Yan, Y. Free-standing and flexible $\mathrm{Cu} / \mathrm{Cu}_{2} \mathrm{O} / \mathrm{CuO}$ heterojunction net: a novel material as cost-effective and easily recycled visible-light photocatalyst. Appl. Catal. B 207, 134-142 (2017).

26. Bersani, M. et al. Combined EXAFS, XRD, DRIFTS, and DFT study of nano copper-based catalysts for $\mathrm{CO}_{2}$ hydrogenation. ACS Catal. 6, 5823-5833 (2016).

27. Lunkenbein, T., Schumann, J., Behrens, M., Schlogl, R. \& Willinger, M. G. Formation of a $\mathrm{ZnO}$ overlayer in industrial $\mathrm{Cu} / \mathrm{ZnO} / \mathrm{Al}_{2} \mathrm{O}_{3}$ catalysts induced by strong metal-support interactions. Angew. Chem. Int. Ed. 54, 4544-4548 (2015).

28. Sápi, A. et al. In situ DRIFTS and NAP-XPS exploration of the complexity of $\mathrm{CO}_{2}$ hydrogenation over size-controlled pt nanoparticles supported on mesoporous NiO. J. Phys. Chem. C. 122, 5553-5565 (2018).

29. Bowker, M. \& Waugh, K. C. From surface science to catalysis: the importance of methoxy and formate species on $\mathrm{Cu}$ single crystals and industrial catalysts. Surf. Sci. 650, 93-102 (2016).

30. Kobl, K. et al. In situ infrared study of formate reactivity on water-gas shift and methanol synthesis catalysts. C. R. Chim. 18, 302-314 (2015).

31. Fujitani, T., Nakamura, I., Uchijima, T. \& Nakamura, J. The kinetics and mechanism of methanol synthesis by hydrogenation of $\mathrm{CO}_{2}$ over a $\mathrm{Zn}$ deposited $\mathrm{Cu}(111)$ surface. Surf. Sci. 383, 285-298 (1997).

32. Weigel, J., Koeppel, R., Baiker, A. \& Wokaun, A. Surface species in CO and $\mathrm{CO}_{2}$ hydrogenation over copper/zirconia: On the methanol synthesis mechanism. Langmuir 12, 5319-5329 (1996).

33. Kattel, S., Yan, B., Yang, Y., Chen, J. G. \& Liu, P. Optimizing binding energies of key intermediates for $\mathrm{CO}_{2}$ hydrogenation to methanol over oxidesupported copper. J. Am. Chem. Soc. 138, 12440-12450 (2016).

34. Martin, O. et al. Operando synchrotron X-ray powder diffraction and modulated-excitation infrared spectroscopy elucidate the $\mathrm{CO}_{2}$ promotion on a commercial methanol synthesis catalyst. Angew. Chem. 128, 11197-11202 (2016).

35. Larmier, $\mathrm{K}$. et al. $\mathrm{CO}_{2}$-to-Methanol hydrogenation on zirconia-supported copper nanoparticles: reaction intermediates and the role of the metal-support interface. Angew. Chem. 129, 2358-2363 (2017).

36. Zhang, Y. et al. Surface-plasmon-driven hot electron photochemistry. Chem. Rev. 118, 2927-2954 (2018).
37. Lindstrom, C. \& Zhu, X.-Y. Photoinduced electron transfer at molecule-metal interfaces. Chem. Rev. 106, 4281-4300 (2006)

38. Beinik, I., Hellström, M., Jensen, T. N., Broqvist, P. \& Lauritsen, J. V. Enhanced wetting of $\mathrm{Cu}$ on $\mathrm{ZnO}$ by migration of subsurface oxygen vacancies. Nat. Commun. 6, 8845 (2015)

39. Grabow, L. C. \& Mavrikakis, M. Mechanism of methanol synthesis on $\mathrm{Cu}$ through $\mathrm{CO}_{2}$ and $\mathrm{CO}$ hydrogenation. ACS Catal. 1, 365-384 (2011).

40. Garcia-Prieto, J., Ruiz, M. \& Novaro, O. Role of excited atomic states in the active sites of transition metals for oxidative and reductive catalytic processes. J. Am. Chem. Soc. 107, 5635-5644 (1985).

41. Dadlani, A. et al. Revealing the bonding environment of $\mathrm{Zn}$ in ALD Zn (O, S) buffer layers through X-ray absorption spectroscopy. ACS Appl. Mater. Interfaces 9, 39105-39109 (2017).

42. Garcia, M. A. et al. Magnetic Properties of $\mathrm{ZnO}$ nanoparticles. Nano Lett. 7, 1489-1494 (2007)

43. French, S. A. et al. From $\mathrm{CO}_{2}$ to methanol by hybrid QM/MM embedding. Angew. Chem. Int. Ed. 40, 4437-4440 (2001).

44. Bahruji, $\mathrm{H}$. et al. $\mathrm{Pd} / \mathrm{ZnO}$ catalysts for direct $\mathrm{CO}_{2}$ hydrogenation to methanol. J. Catal. 343, 133-146 (2016).

45. Frisch M. et al. Gaussian 16 Revision B. 01. 2016 (Gaussian Inc. Wallingford CT).

46. Perdew, J. P., Burke, K. \& Ernzerhof, M. Generalized gradient approximation made simple. Phys. Rev. Lett. 77, 3865 (1996).

47. Krishnan, R., Binkley, J. S., Seeger, R. \& Pople, J. A. Self-consistent molecular orbital methods. XX. A basis set for correlated wave functions. J. Chem. Phys. 72, 650-654 (1980).

48. Frisch, M. J., Pople, J. A. \& Binkley, J. S. Self-consistent molecular orbital methods 25. Supplementary functions for Gaussian basis sets. J. Chem. Phys. 80, 3265-3269 (1984).

49. Kresse, G. \& Furthmüller, J. Efficiency of ab-initio total energy calculations for metals and semiconductors using a plane-wave basis set. Comput. Mater. Sci. 6, 15-50 (1996).

50. Kresse, G. \& Furthmüller, J. Efficient iterative schemes for ab initio totalenergy calculations using a plane-wave basis set. Phys. Rev. B 54, 11169 (1996).

51. Monkhorst, H. J. \& Pack, J. D. Special points for Brillouin-zone integrations. Phys. Rev. B 13, 5188 (1976).

\section{Acknowledgements}

The work was supported by the Australian Research Council (ARC) under the Laureate Fellowship Scheme-FL140100081. The authors would also like to acknowledge the use of facilities within the UNSW Mark Wainwright Analytical Centre and the UoW Electron Microscopy Centre. UK Catalysis Hub is kindly thanked for resources and support provided via our membership of the UK Catalysis Hub Consortium and funded by EPSRC grant: EP/R026939/1, EP/R026815/1, EP/R026645/1, EP/R027129/1 or EP/ M013219/1(biocatalysis)). This research has been performed with the use of facilities at the Research Complex at Harwell including Parr high pressure flow reactor, Agilent GCMS, Harrick Scientific Praying Mantis high temperature reaction chamber, LOT Oriel Gruppe Europa Xenon arc lamp, and Belle inert glovebox. The authors would like to thank the Research Complex for access and support to these facilities and equipment. XAFS measurements were performed on the B18 Core EXAFS beamline at Diamond Light Source as part of the Block Allocation Group (BAG) access SP19850. R.J.W.'s work at Diamond Light Source was partially supported by the Australian Synchrotron. We acknowledge travel funding provided by the International Synchrotron Access Program (ISAP) managed by the Australian Synchrotron, part of ANSTO, and funded by the Australian Government. M.H. acknowledges the GCRF START project (ST/R002754/1) for funding support. M. H. also acknowledges the support of the Supercomputing Wales project, which is part-funded by the European Regional Development Fund (ERDF) via Welsh Government, and STFC Scientific Computing Department's SCARF cluster, for the provision of computational resources. We would like to thank Mark Isaacs for his assistance with XPS measurements at Research Complex at Harwell. We also acknowledge the fruitful discussion with Alexey Sokol and David Mora-Fonz from University College London and the technical support from Diego Gianolio, Veronica Celorrio, and Giannantonio Cibin from Diamond Light Source.

\section{Author contributions}

B.X. and R.J.W. have equal contributions in this work. B.X., R.J.W., T.H.T., J.S., and R.A conceived and designed the experiments, with input and support from R.C., M.B., and J.C. B.X. and R.J.W. synthesised and characterised the catalysts with inputs from T.H.T., J.S., and R.A. B.X. performed the in situ DRIFTS experiments with the support of T.H.T and K.-F.A.-Z. Further analysis of spectral data was conducted and interpreted by B.X., T.H.T., and R.J.W. R.J.W. performed the XPS measurements and analysis while B.X. assisted in the data processing. R.J.W., D.D., and J.C. performed the XAFS measurements and data processing with the support from E.G. Further data analysis was finished by B.X. and R.J.W. M.H. did the computational work and related analysis parts were completed by M.H., R.J.W., B.X., and R.C. B.X., R.J.W., J.S., and R.A. wrote the article. All 
authors contributed to the completion of the manuscript. All authors discussed the results and commented on.

\section{Competing interests}

The authors declare no competing interests.

\section{Additional information}

Supplementary information is available for this paper at https://doi.org/10.1038/s41467020-15445-z.

Correspondence and requests for materials should be addressed to J.S. or R.A.

Peer review information Nature Communications thanks Hanna Härelind, Le He and the Päivi Mäki-Arvela for their contribution to the peer review of this work. Peer reviewer reports are available.

Reprints and permission information is available at http://www.nature.com/reprints
Publisher's note Springer Nature remains neutral with regard to jurisdictional claims in published maps and institutional affiliations.

(c) (i) Open Access This article is licensed under a Creative Commons Attribution 4.0 International License, which permits use, sharing, adaptation, distribution and reproduction in any medium or format, as long as you give appropriate credit to the original author(s) and the source, provide a link to the Creative Commons license, and indicate if changes were made. The images or other third party material in this article are included in the article's Creative Commons license, unless indicated otherwise in a credit line to the material. If material is not included in the article's Creative Commons license and your intended use is not permitted by statutory regulation or exceeds the permitted use, you will need to obtain permission directly from the copyright holder. To view a copy of this license, visit http://creativecommons.org/ licenses/by/4.0/.

(c) Crown 2020 